\title{
Main Line Fault Localization Methodology (MLFLM) in Smart Grid - The Underground Medium- and Low-Voltage Broadband over Power Lines Networks Case
}

\author{
Athanasios G. Lazaropoulos* \\ School of Electrical and Computer Engineering / National Technical University of Athens / \\ 9 Iroon Polytechniou Street / Zografou, GR 15780
}

Received November 24, 2017; Accepted December 22, 2017; Published December 29, 2017

\begin{abstract}
This paper assesses the performance of the main line fault localization methodology (MLFLM) when its application is extended to underground medium- and low-voltage broadband over power lines (UN MV and UN LV BPL) networks, say UN distribution BPL networks.

This paper focuses on the localization of main distribution line faults across UV MV and UN LV BPL networks. By extending the MLFLM procedure, which has successfully been applied to overhead medium-voltage (OV MV) BPL networks, the performance assessment of MLFLM is investigated with respect to the nature of the main distribution line faults, the intensity of the measurement differences and the fault location across the main distribution lines of the underground distribution power grid (either MV or LV grid).
\end{abstract}

Keywords: Smart Grid; Intelligent Energy Systems; Broadband over Power Lines (BPL) Networks; Power Line Communications (PLC); Faults; Fault Analysis; Fault Localization; Distribution Power Grids

\section{Introduction}

Thanks to the broad coverage of power grids and the low cost deployment of broadband over powerlines (BPL) system architecture, broadband over powerlines (BPL) networks act as a convenient technology solution in the emerging cooperative communications network of Smart Grid [1]. Compared against the other wired and wireless communications technologies that already interoperate in the Smart Grid, BPL networks can more easily deal with the "last mile" and "last-inch" problems since BPL networks are capable of providing broadband communications access to isolated places with significant broadband speeds by exploiting the already installed power grid infrastructure [2]. Another strong argument of the BPL technology is that its network components are already standardized systems by IEEE Std 1901 [3], which defines a standard for all BPL devices that are deployed across the transmission, distribution and indoor power grids including BPL devices used for various smart grid applications.

Since the transmission and distribution power grids were not originally intended for conveying high frequency signals, several adversarial factors, such as high frequency-selective channel attenuation and noise, foment the venture of communications signal propagation and transmission by severely deteriorating the quality of the supported 
smart grid applications [4]-[10]. Apart from the inherent deficiencies of BPL networks, whose impact has thoroughly been examined in [4]-[8], [11]-[23], measurement differences, faults and instabilities of the power grid further deteriorate the broadband performance of BPL networks.

Until now, significant efforts have been made to counteract measurement differences and identify / localize faults and instabilities that may occur across the transmission and distribution power grids. Initially, a great convenience towards the aforementioned problems has been offered by the combined operation of the well-established hybrid method [4]-[8], [11]-[23] with piecewise monotonic data approximations (PMAs), such as L1PMA, L2WPMA and L2CXCV [24]-[32]. Their application to measurement data, such as channel attenuations and reflection coefficients, has allowed the restoration of theoretical transfer functions and the reflection coefficients, respectively, even if measurement differences of various intensities may occur [21], [33]-[36]. On the basis of the mitigation of measurement differences and the retrieval of the transfer functions and reflection coefficients for a given BPL topology, Topology Identification Methodology (TIM) suggests that the determination of the topological characteristics of the examined topology is a straightforward process through an identification procedure that compares PMA approximated data with the respective ones of a detailed BPL topology database [22], [37]. Another recently proposed smart grid application, which is supported by BPL networks and the combined operation of the hybrid method with PMAs, is the Fault and Instability Identification Methodology (FIIM) that deals with the identification and localization of various faults and instabilities that may occur across the transmission and distribution power grids, such as faults in branch lines, instabilities in branch interconnections and instabilities in branch terminations [37]. However, the only case that cannot be examined by FIIM is the identification and localization of main distribution line faults that have been covered by the Main Line Fault Localization Methodology (MLFLM) presented in [33], [34], [38].

Utilities employ either overhead or underground lines for implementing their distribution power grids for new urban, suburban and rural installations in accordance with different criteria like cost requirements, existing grid topology and urban plan constraints [8]. Until now, the previous smart grid applications have mainly applied to overhead transmission and distribution BPL networks. The main interest of this paper is the application and assessment of MLFLM to UN distribution power grids that are supported by BPL networks. In this paper, the pieces of experience concerning the identification and localization of main distribution line faults across overhead medium-voltage (OV MV) BPL networks is here extended in UN BPL networks, namely: (i) The extended TM2 method of [33], which is suitable for determining the reflection coefficients during the main distribution line fault cases, is here applied. (ii) The application of PMAs, such as L1PMA, that is used in order to mitigate the destructive role of measurement differences during the identification / localization of main distribution line faults of UN BPL networks is also done [34]. Anyway, the identification procedure through the application of the main distribution line fault identification percentage metric (MDLFI) is omitted in this paper, since a main distribution line fault across UN BPL network is assumed de facto; and (iii) all the properties of MLFLM, which have been thoroughly presented in [38], are also adopted in this paper. In order to push forward the knowledge frontier of [33], [34], [38], the following innovations are made in this paper: (a) the detailed database of coupling reflection coefficients and respective MDLFIs of [38] are reconstructed for all 
the possible UN MV and UN LV BPL topologies. As in OV MV BPL networks of [33], [34], [38], the database also takes into account the nature of the main distribution line faults; (b) MLFLM procedure is tailored to UN BPL networks. Three new submethods, that accompany MLFLM and MDLFIs, are proposed in order to cope with the more challenging cases that can arise in UN distribution BPL networks during the localization of main distribution line faults; and (c) the MLFLM efficiency is evaluated while MLFLM results of UN BPL networks against measurement differences and main distribution line faults are compared versus the respective ones of OV MV BPL networks.

The rest of this paper is organized as follows: In Sec.II, the findings of [33], [34], [38], which concern UN BPL networks, PMAs and MDLFI, that are used in this paper are briefly outlined. In Sec.III, the required modifications concerning MLFLM application are demonstrated. Sec.IV assesses MLFLM efficiency in UN MV and UN LV BPL networks when measurement differences and main distribution line faults occur. Finally, the results of MLFLM application n UN BPL networks are compared against the respective ones of OV MV BPL networks. Sec.V concludes this paper.

\section{Brief Presentation of UN BPL Networks, PMAs and MDLFI}

\subsection{MTL Configurations of UN MV and UN LV Lines}

As concerns the MTL configuration of the examined UN MV BPL networks of this paper, the UN MV distribution line is the three-phase sector-type PILC distribution-class cable of Fig. 1(a). The cable arrangement consists of the three-phase three-sector-type conductors $\left(n^{\mathrm{UNMV}}=3\right)$, one shield conductor and one armor conductor. To electrostatically and magnetostatically protect the inner conductors, both the shield and the armor are grounded at both ends [6], [14], [39]-[43]. Apart from the aforementioned protection, the analysis in UN MV configurations is based on the consideration of the shield conductor as the reference one thus allowing the analysis to be focused only on the inner MTL set that consists of the three phases and the shield. Details about the exact dimensions of the UN MV MTL configuration of Fig. 1(a) are given in [14].

As concerns the MTL properties of the UN LV configuration, the UN LV distribution line that is examined is the three-phase four-conductor $\left(n^{\mathrm{UNLV}}=3\right)$ core-type XLPE distribution cable of Fig. 1(b). This cable arrangement consists of the three-phase three-core-type conductors, one core-type neutral conductor and one shield conductor. As it has already been assumed in the UN MV case, the shield is grounded at both ends and considered as the reference conductor permitting the analysis of UN LV configuration to be exclusively concentrated on the inner set of the UN LV cable [19], [20], [42]-[48]. The exact dimensions of the UN LV MTL configuration, which is used in the present work, are given in [14]. 


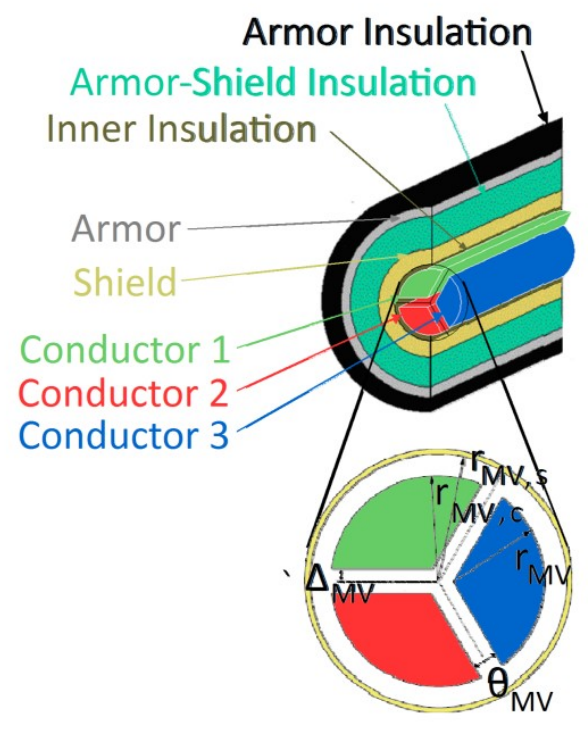

(a)

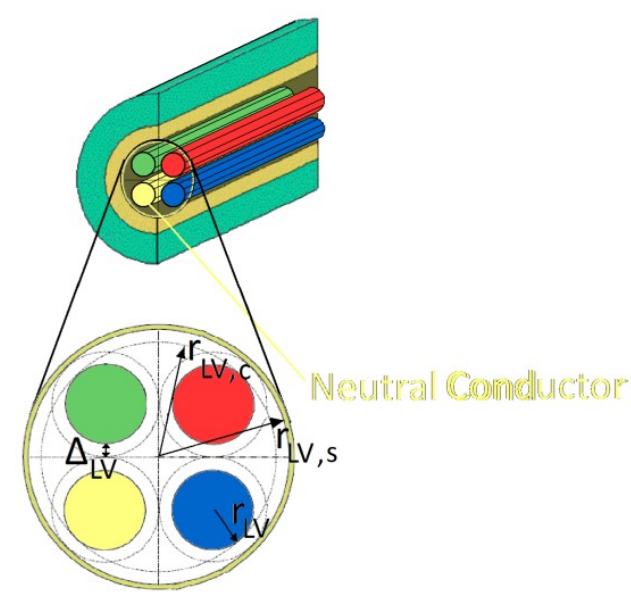

(b)

Fig. 1. Typical MTL structures [14], [43]. (a) UN MV. (b) UN LV.

The analytical formulation, which is adopted in this paper for the signal propagation analysis in UN distribution BPL systems, considers high frequency transmission in the general case of UN power lines consisting of multiple conductors surrounded by one common shield [6], [7], [19], [20], [42], [47], [49].

\subsection{Topologies of UN MV and UN LV BPL Networks}

The typical UN BPL topology of Fig. 2, being bounded by transmitting and receiving end and having $N$ branches, is considered for the examined UN BPL connections of this paper. With reference to Fig. 2, average path lengths of the order of 200m are considered in UN MV and UN LV topologies [6], [7], [11], [12]. In fact, the definition of a maximum path length in UN BPL networks prevents high channel attenuations that may eliminate the broadband potential of BPL networks. Depending on the number of branches and their allocation across the transmission path, five indicative UN BPL topologies are defined that act as representative topologies of the respective UN BPL classes, namely [14]:

(i) A typical underground urban topology (urban case A) with $N=3$ branches ( $\left.L_{1}=70 \mathrm{~m}, L_{2}=55 \mathrm{~m}, L_{3}=45 \mathrm{~m}, L_{4}=30 \mathrm{~m}, L_{\mathrm{b} 1}=12 \mathrm{~m}, L_{\mathrm{b} 2}=7 \mathrm{~m}, L_{\mathrm{b} 3}=21 \mathrm{~m}\right)$.

(ii) An aggravated underground urban topology (urban case B) with $N=5$ branches $\left(L_{1}=40 \mathrm{~m}, L_{2}=10 \mathrm{~m}, L_{3}=20 \mathrm{~m}, L_{4}=40 \mathrm{~m}, L_{5}=60 \mathrm{~m}, L_{6}=30 \mathrm{~m}, L_{\mathrm{b} 1}=22 \mathrm{~m}, L_{\mathrm{b} 2}=12 \mathrm{~m}\right.$, $\left.L_{\mathrm{b} 3}=8 \mathrm{~m}, L_{\mathrm{b} 4}=2 \mathrm{~m}, L_{\mathrm{b} 5}=17 \mathrm{~m}\right)$.

(iii) A typical underground suburban topology (suburban case) with $N=2$ branches ( $\left.L_{1}=50 \mathrm{~m}, L_{2}=100 \mathrm{~m}, L_{3}=50 \mathrm{~m}, L_{\mathrm{b} 1}=60 \mathrm{~m}, L_{\mathrm{b} 2}=30 \mathrm{~m}\right)$.

(iv) A typical underground rural topology (rural case) with only $N=1$ branch $\left(L_{1}=50 \mathrm{~m}, L_{2}=150 \mathrm{~m}, L_{\mathrm{bl}}=100 \mathrm{~m}\right)$. 


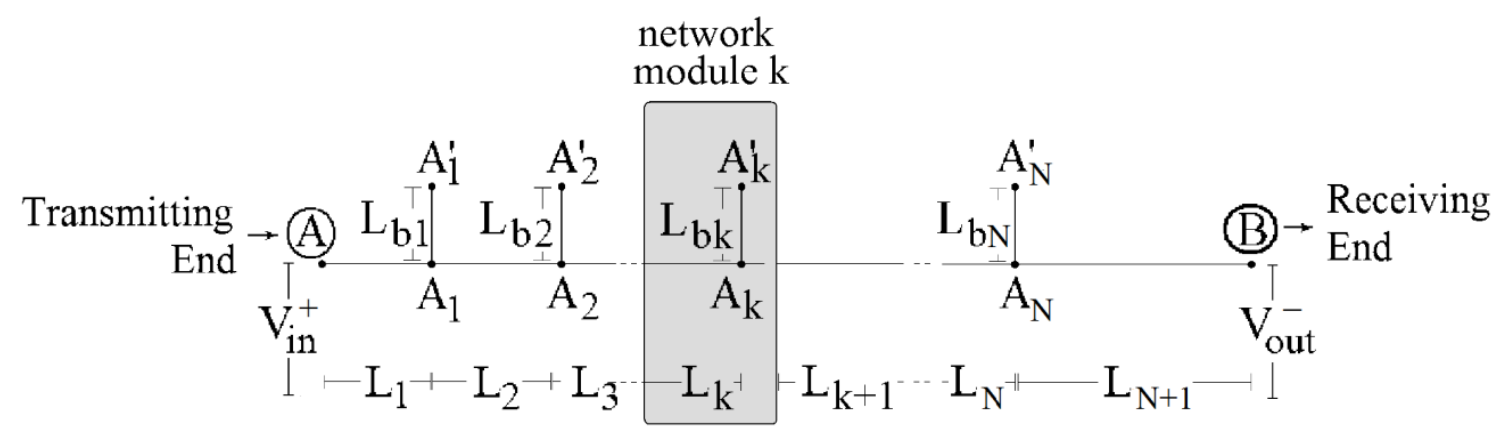

Fig. 2. Typical UN BPL topology with $N$ branches.

(v) The underground "LOS" transmission ("LOS" case) along the same end-to-end distance $L=L_{1}+\cdots+L_{\mathrm{N}+1}=200 \mathrm{~m}$ when no branches are encountered.

Here, it should be noted that the aforementioned five indicative UN BPL topologies remain common either in UN MV or in UN LV BPL connections. Apart from the topological properties of UN BPL connections, the circuital parameters need to be detailed. In accordance with [4], [5]-[7], [14], [16], [18], [19], [39], [44], [45], [47], [48], [50]-[52], the branching cables are assumed identical to the main distribution cables and the interconnections between the main distribution and branch conductors are fully connected. Also, the transmitting and the receiving ends are assumed matched to the characteristic impedance of the modal channels whereas the branch terminations are assumed open circuit.

Since the MTL configuration and the topological characteristics of UN BPL networks are already known, the well-established hybrid method that consists of: (i) a bottom-up approach that is based on the MTL theory and eigenvalue decomposition (EVD); and (ii) a top-down approach that is denoted as TM2 method and is based on the concatenation of multidimensional chain scattering matrices; is applied in order to determine the coupling channel attenuation and coupling reflection coefficients of UN BPL channels. More specifically, to cope with the main distribution line faults, the extended TM2 method has been proposed in [33] and tested in [34], [38]. Extended TM2 method is the required extension of the well-verified original TM2 method [4]-[8], [11]-[20], [47], [53], [54] since original TM2 method only deals with the transmission properties of BPL networks during their normal operation and not at the fault cases. While extended TM2 method receives the same inputs with original TM2 method, it gives as output the coupling reflection coefficients of an UN BPL network at its transmitting end when a main distribution line fault occurs across its transmission path.

\subsection{Main Distribution Line Faults and Measurement Differences}

Similarly to OV MV grids of [33], [34], [38], critical problematic conditions, such as the main distribution line faults, can occur across the UN distribution power grids having as primary result the electric power distribution blackout to consumers and as secondary result the interruption of smart grid broadband services that are based on the BPL networking. In accordance with [38], since a main distribution line fault occurs at a specific distance from the transmitting end, the original UN BPL topology is then divided into two new modified UN BPL topologies with each path length being equal or shorter 
than $200 \mathrm{~m}$ but the path length sum being equal to $200 \mathrm{~m}$. These two modified UN BPL topologies maintain as the only common point between them the point of the main distribution line fault. In order to study the propagation and transmission behavior of the modified UN BPL topologies, the main distribution line fault point is treated as a termination load that behaves as either short- or open-circuit termination depending on the fault nature. Here, it should be noticed that the original UN BPL topologies are characterized by terminal loads that are matched to the characteristic impedances of the modes examined. As proven in [38], the localization of main distribution line faults by using MLFLM becomes more effective when both modified UN BPL topologies are examined. Therefore, pairs of complementary modified UN BPL topologies to the original one are used whose topological characteristics primarily depend on the location of the main distribution line fault and the fault nature.

As presented in [34], [38], the identification and localization of main distribution line faults remain an easy and straightforward task only in the cases of zero measurement differences. However, this case remains rather a theoretical and special situation since measurement differences of various intensities occur that vary from time to time and location to location even across the same UN BPL topology.

Apart from the main distribution line faults, the existence of measurement differences may jeopardize the fault localization of MLFLM as indicated in [38]. In accordance with [22], the causes of the presented measurement differences can be grouped into six categories, namely: (i) Isolation difficulties of specific MTL parameters in time- and frequency-domain; (ii) Low accuracy and sensitivity of the used equipment during measurements; (iii) Cross-talk and resonant phenomena due to the parasitic capacitances and inductances of lines; (iv) The weakness of including specific wiring and grounding practices; (v) Practical impedance deviations of lines, branches, terminations and transmitting/receiving ends; and (vi) The isolation lack of the noise effect during the transfer function computations.

The strong point of MLFLM towards the mitigation of measurement differences is the adoption of PMAs during the process of measurement data of channel attenuation and coupling reflection coefficient in BPL networks [21]-[23], [33]-[38]. The application of PMAs, such as L1PMA [24]-[30], L2WPMA [31] and L2CXCV [32], drastically improve the fault localization efficiency even in the case of significant measurement differences. When MLFLM is going to be applied, MLFLM receives as inputs for its PMA module the coupling reflection coefficient data of UN distribution BPL topologies, the measurement frequencies and the number of monotonic sections while MLFLM gives as output the main distribution line fault identification percentage metric (MDLFI) with respect to the distance from the transmitting end for the complimentary modified UN BPL topologies. In fact, MDLFI is a MLFLM accompanying performance metric, has been proposed in [23], [34], [37], [38] and is suitable for the identification and localization of main distribution line faults across BPL networks. On the basis of MDLFI minima, the localization of main distribution line faults is going to be accomplished in UN BPL networks.

\subsection{MDLFI, MLFLM Database and Localization Procedure}

According to the results of [33], [38], the main distribution line fault localization efficiency of MLFLM depends on the magnitude of the measurement differences and the complexity of the examined BPL topology. In fact, one main advantage of MLFLM is the 
application of MDLFI metric to each pair of the available modified BPL topologies of MLFLM database bypassing the inherent drawback of MDLFI that is the MDLFI selective behavior with respect to the fault distance from the transmitting end (for more details see [33]).

Using both the available two coupling reflection coefficient measurement sites, which are the transmitting and receiving ends of the examined original UN BPL topology, to define the respective modified UN BPL topologies, the simultaneous minimization of the two MDLFIs (say, MDLFI ${ }_{1}$ and $\mathrm{MDLFI}_{2}$ ) leads to the exact localization of the main distribution line fault. Similarly to MDLFI of [38], $\mathrm{MDLFI}_{k}, k=1 \ldots 2$ of the respective two modified UN BPL topologies are given by

$$
M D L F I_{k}=\frac{\sum_{k_{\text {sect }}=1}^{20} M D L F I_{\mathrm{par}, k}\left(k_{\mathrm{sect}}\right)}{600}, k=1 \ldots 2
$$

where

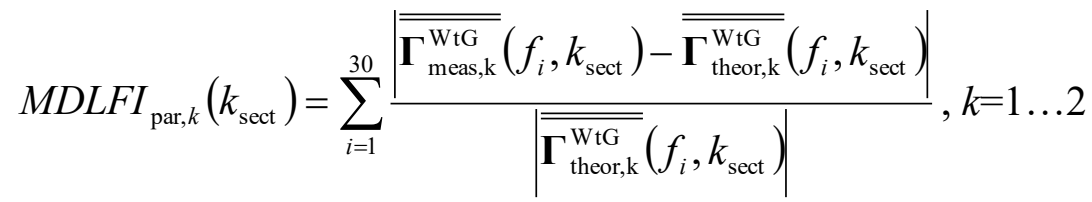

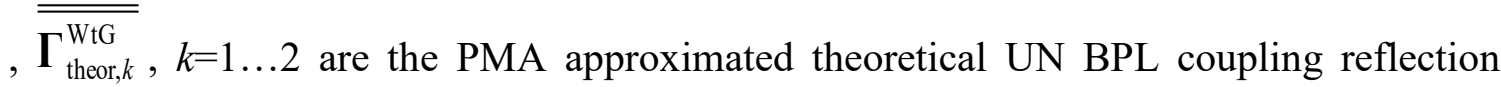
coefficient column vectors of the respective two modified UN BPL topologies, $\overline{\overline{\Gamma_{\text {meas }, k}^{\mathrm{WtG}}}}, k=1 \ldots 2$ are the PMA approximated measured UN BPL reflection coefficient column vectors of the respective two modified UN BPL topologies, $f_{i}, i=1, \ldots, 30$ are the measurement frequencies and $k_{\text {sect }}$ is the number of monotonic sections considered in this paper, which ranges from 1 to 20 .

As detailed in [38], PMA approximated theoretical UN BPL coupling reflection coefficient column vectors are computed for all the available modified UN BPL topologies when the original UN BPL topology is known. In order to implement the MLFLM database that consists of all these pairs of modified UN BPL topologies as well as their coupling reflection coefficients, the first step is the consideration of the length spacing $L_{\mathrm{s}}$ of main distribution line faults. Since the average transmission length is equal to $200 \mathrm{~m}$ and the length spacing $L_{\mathrm{s}}$ that defines the database accuracy is assumed equal to $10 \mathrm{~m}$ in this paper, there are $\left(\frac{200 \mathrm{~m}}{10 \mathrm{~m}}\right)+1=21$ pairs of modified UN BPL topologies for given original UN BPL topology. Except for the database properties regarding the number of the considered UN BPL topologies, a set of database specifications is here given [22], [38]:

- $k_{\text {sect,min }}$ is the lower monotonic section bound, which is assumed to be equal to 1 in this paper, and $k_{\text {sect,max }}$ is the upper monotonic section bound, which is assumed to be equal to 20 in this paper.

- The operation frequency range and the flat fading subchannel frequency spacing are assumed equal to $1-30 \mathrm{MHz}$ and $1 \mathrm{MHz}$, respectively. Therefore, the number of subchannels $u$ in the examined frequency range is equal to 30 . 
- Arbitrarily, the $\mathrm{WtG}^{3}$ coupling scheme is applied during the following simulations [6], [18], [55]-[58].

- For each UN BPL topology that is considered in the database, the two cases of termination loads that are short- and open-circuit terminations are considered.

Based on the measured coupling reflection coefficients of the modified OV MV BPL topologies, the theoretical coupling reflection coefficients of all the available modified OV MV BPL topologies of the MLFLM database and MDLFIs of the set of the respective modified OV MV BPL topologies, MLFLM has achieved to exactly localize the main distribution line faults across original OV MV BPL topologies [33], [34], [38]. Here, MLFLM is applied to UN MV and UN LV BPL networks by exploiting the validated strong points concerning the handling of MDLFIs; say, the double coupling reflection coefficient measurement sets (i.e., the first set from the transmitting end side and the other one from the receiving end side of the original UN BPL topology) of the MLFLM database and the simultaneous minimization of MDLFIs. Since each set of coupling reflection coefficients accompanies the topological characteristics of the respective set of modified UN BPL topologies in the database, the exact location of the main distribution line fault across the original UN BPL topology is a straightforward process. Visually, the exact location of the main distribution line fault is found by studying the graphical representation of MDLFIs versus the distance from the transmitting end and spotting the location where MDLFIs simultaneously present their minimum value.

\section{Numerical Results and Discussion}

The five original UN BPL topologies of Sec. 2.2, which remain common for both UN MV and UN LV cases, are simulated with the purpose of evaluating the MLFLM performance when main distribution line faults occur and require to be localized across UN distribution power grids. A number of factors such as the type of distribution power grid (say, either UN MV or UN LV), the complicity of the original UN BPL topology, the nature of the terminal load and the location of main distribution line fault are examined. Similarly to [38], the combined impact of measurement differences and main distribution line faults is examined. In order to study this combined result, the following conditions concerning the measurement differences and main distribution line faults are considered, namely:

- The measurement differences that occur during the determination of coupling reflection coefficients in UN MV and UN LV topologies are described by continuous uniform distributions (CUDs) with maximum CUD value $\alpha_{\mathrm{MD}}$. In accordance with [38], three different measurement difference CUDs are taken into account:

- CUD with $a_{\mathrm{MD}}=0$ (no measurement differences are assumed while this CUD case is denoted as CUD case A);

$\circ$ CUD with $a_{\mathrm{MD}}=0.1$ (denoted as CUD case B); and

- CUD with $a_{\mathrm{MD}}=0.2$ (denoted as CUD case $\mathrm{C}$ ).

- To study the impact of main distribution line faults on the MLFLM performance, three representative fault locations are given:

$\circ$ Fault located at $20 \mathrm{~m}$ from the transmitting end (denoted as Fault case A); 
- Fault located at $90 \mathrm{~m}$ from the transmitting end (denoted as Fault case B); and

- Fault located at 190m from the transmitting end (denoted as Fault case C).

Prior to assess the MLFLM performance, it is assumed that the existence of a main distribution line fault across the UN distribution power grid has been already identified but not localized.

\subsection{The Impact of the Maximum CUD Value of Measurement Differences on the Fault Localization by Applying MLFLM}

As indicated in [38], the successful application of MLFLM is achieved by spotting the simultaneous minimization of MDLFIs across the transmission path. The location of the previous simultaneous minimization defines the main distribution line fault location. Although MLFLM is very accurate when no measurement differences are considered, MLFLM satisfactorily localizes main distribution line faults even if measurement differences of various CUD magnitudes are assumed. MLFLM performance of fault localization in UN MV and UN LV BPL networks is investigated in this subsection.

In Fig. 3(a), MDLFIs of the urban UN MV BPL topology of case A are plotted versus the distance from the transmitting end when the terminal load is assumed to be short-circuit during the main distribution line fault case A for CUD case A, B and C. In Fig. 3b, same plots are drawn with Fig. 3(a) but for the case of an open-circuit terminal load. In Figs. 4(a) and 4(b), same plots with the respective Figs. 3(a) and 3(b) are given but for the case of the urban UN LV BPL topology of case A.

It is obvious that the localization of main distribution line faults across UN distribution BPL networks becomes easier when measurement differences remain low. From Figs. 3(a), 3(b), 4(a) and 4(b), it is verified that the fault localization performance remains high even if decent measurement differences occur (i.e., measurement differences with maximum CUD magnitude up to 0.2). Hence, MLFLM performance towards the localization of main distribution line faults presents relative immunity against the factors that affect the accuracy of measurement equipment.

As presented in [38], MDLFIs of UN distribution BPL networks present similar behavior with the respective one of MDLFIs of OV BPL networks. When measurement differences are negligible, both MDLFIs achieve their minimum values that are equal to 0 . As the measurement differences increase so do MDLFIs but their values at the position of the main distribution line fault remain the lowest in comparison with the other MDLFI values for given maximum CUD magnitude. Here, it should be noted that significant measurement differences can deteriorate MLFLM performance since the localization of the main distribution line faults in these cases may affect the simultaneous minimization of MDLFIs.

According to [6], [11], [12], [16], by comparing channel attenuations of UN distribution BPL channels, it is evident that the channel attenuation of UN MV BPL channels is significantly higher than the one of UN LV BPL channels. This channel attenuation difference is primarily due to the insulation characteristics of the considered UN MV cables -i.e., paper-insulated lead covered (PILC) distribution cables-. Apart from the channel attenuation, coupling reflection coefficients and the respective 


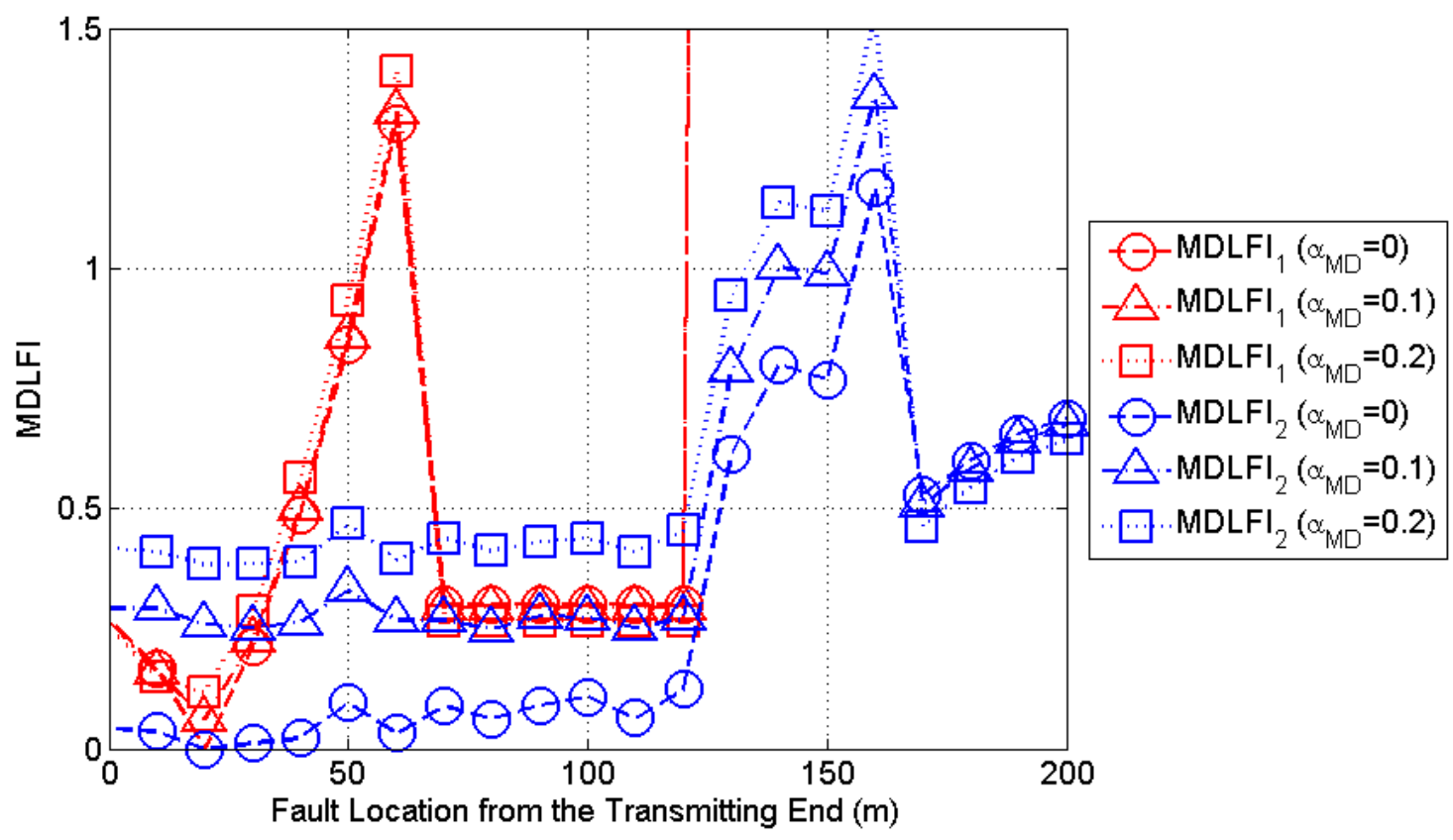

(a)

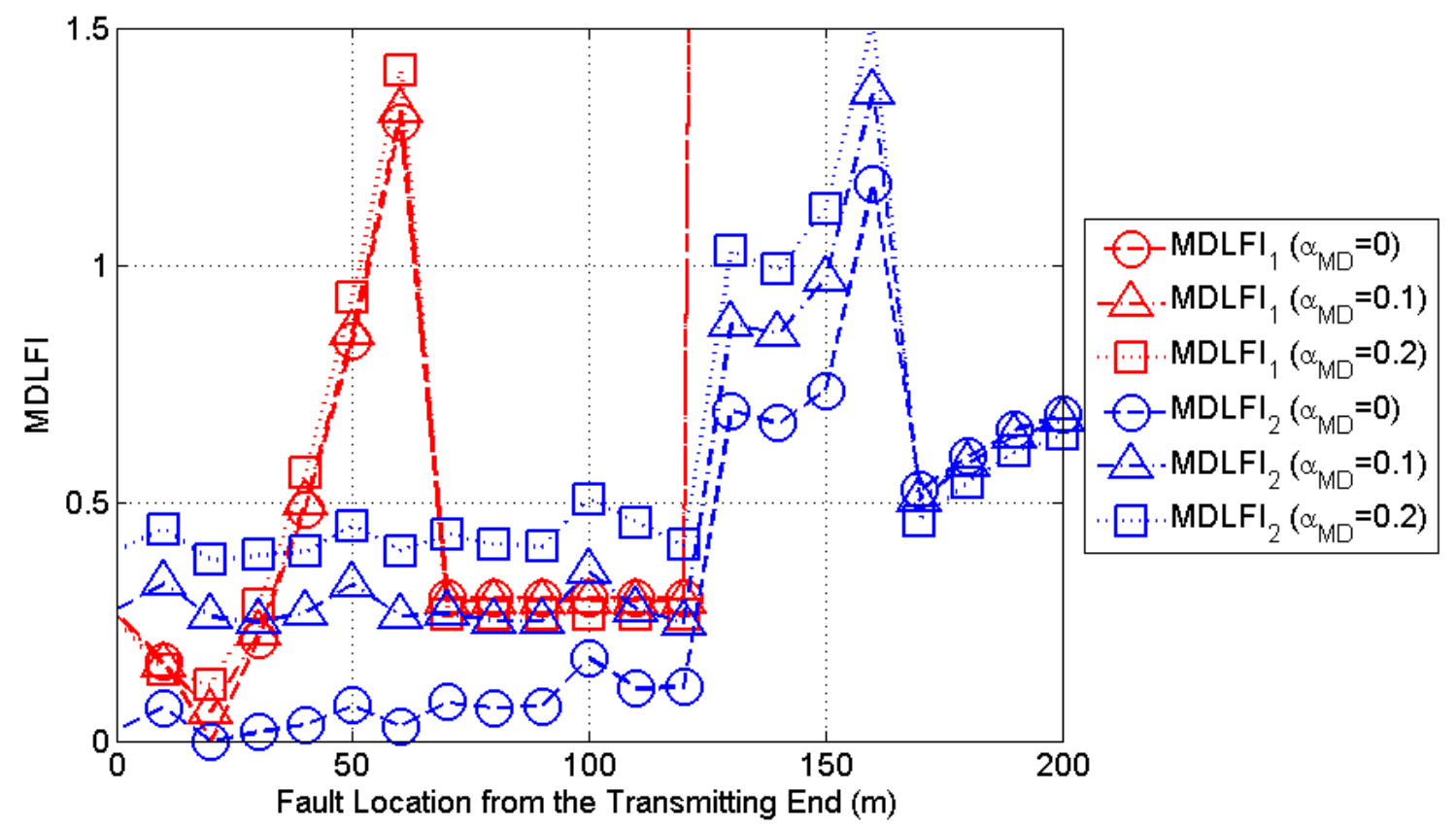

(b)

Figure 3. MDLFIs of the urban UN MV BPL topology versus the fault location from the transmitting end for various CUD magnitudes when fault case $A$ is applied (fault location at $20 \mathrm{~m}$ ). (a) Short-circuit terminal load (b) Open-circuit terminal load. 


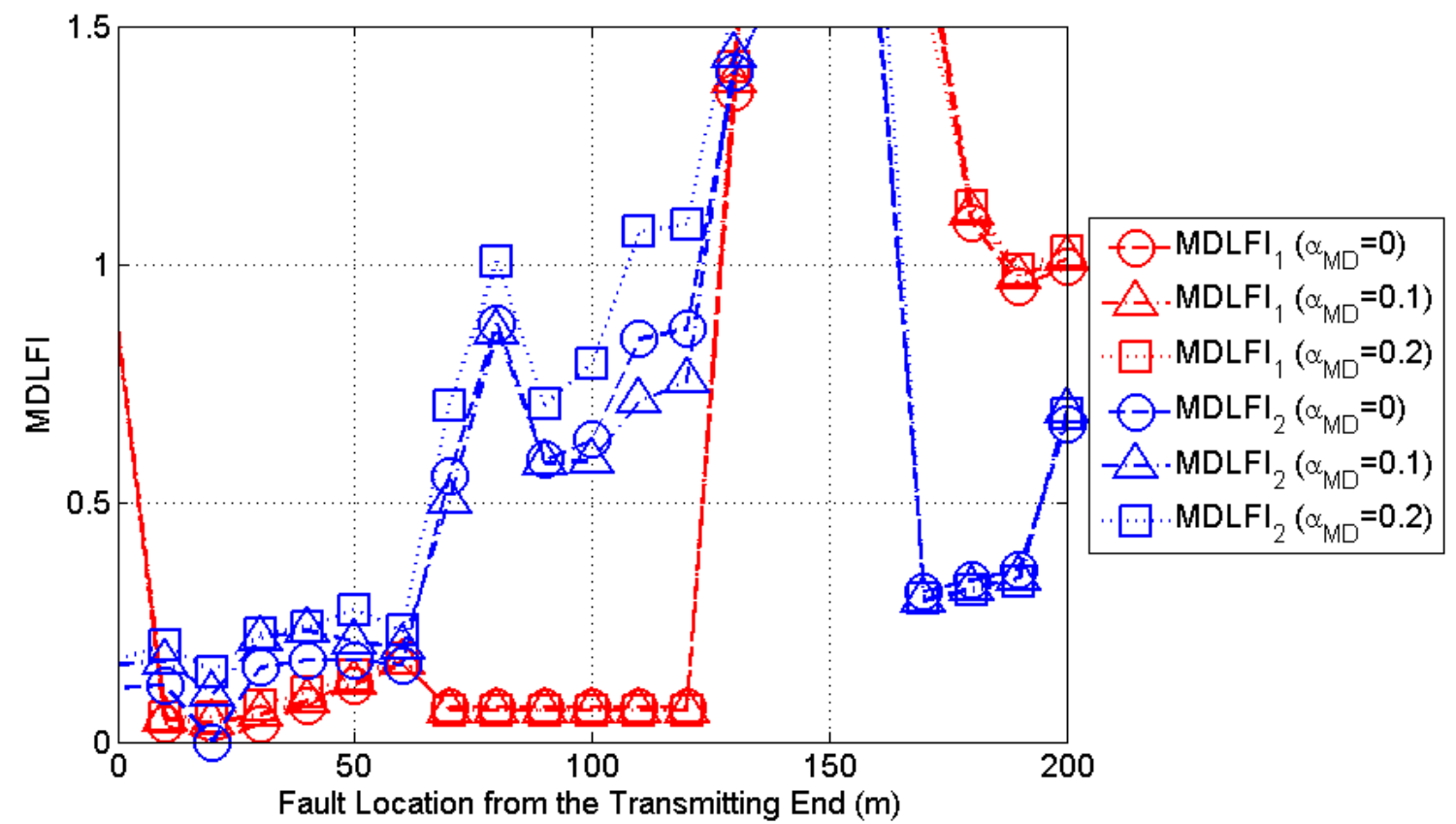

(a)

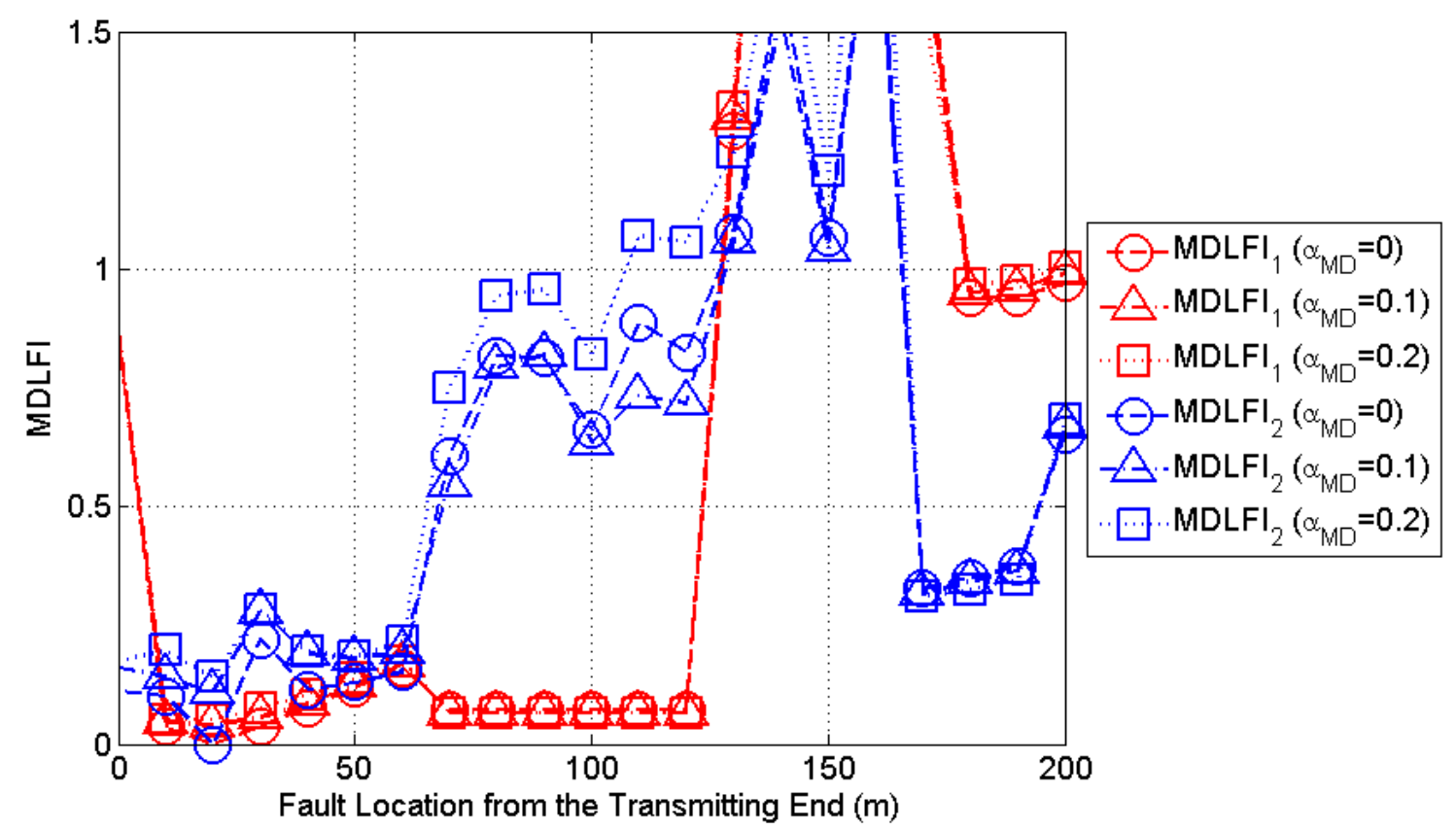

(b)

Figure 4. Same curves with Figure 3 but for the case of the urban UN LV BPL topology.

MDLFIs are also affected by the insulation characteristics of the considered UN MV BPL cables; MDLFIs of UN LV BPL topologies present lower values than the respective ones of UN MV BPL topologies. Since coupling reflection coefficients of UN MV BPL channels are low enough, the measurement differences that are superimposed to the coupling reflection coefficients have strong effect to the overall coupling reflection coefficients. Hence, measurement differences become less critical during the localization 
of main distribution line faults in UN LV BPL topologies and, for that reason, MDLFIs of UN LV BPL topologies achieve better simultaneous MDLFI minimizations for different intensities of measurement differences -compare MDLFI ${ }_{1}$ and $\mathrm{MDLFI}_{2}$ curves of Figs. 3(a) and 3(b) with the respective ones of 4(a) and 4(b)-.

Regardless of the type of the examined UN distribution power grid, the minima of MDLFIs define the location of the main distribution line fault through their simultaneous appearance. It is clear that the simultaneous minimization of MDLFIs at the location of the main distribution line faults is secured when the measurement differences remain low. Divergences may occur only in the cases of measurement differences that are characterized by high intensities - see $\mathrm{MDLFI}_{2}$ of Fig. 3(a) and 3(b) when maximum CUD magnitude is equal to $0.2-$. In these cases, the location of the main distribution line fault can be fulfilled by using two newly proposed submethods that cooperatively act with MLFLM:

- MDLFI area method. In accordance with this method, the main distribution line fault lies in the area that is bounded by the two minima of MDLFIs. Example of the MDLFI area case is given in Figs. 3(a) and 3(b) for maximum CUD magnitudes exceeding 0.1 where $\mathrm{MDLFI}_{1}$ gives the exact location of the main distribution line fault (left bound of the MDLFI area) while minimum of $\mathrm{MLDFI}_{2}$ offers the right bound of the MLDFI area.

- MDLFI sum minimization. The general form of the MDLFI curves may reveal the fault location. In these cases, the minimum of the sum of $\mathrm{MDLFI}_{1}$ and $\mathrm{MDLFI}_{2}$ indicates the location of the main distribution line fault.

Also, a rule of thumb that is suitable for the localization of the main distribution line faults when significant differences between $\mathrm{MDLFI}_{1}$ and $\mathrm{MDLFI}_{2}$ occur is given in Sec. 3.3 and is based on the MDLFI that is closer to the main distribution line fault.

Finally, the nature of the main distribution line fault, as reflected on the terminal load, slightly affects the MLFLM performance. In fact, the main distribution line faults across UN distribution BPL networks can be either short- or open-circuit terminal load depending on the fault nature. Since MLFLM performance remains almost immune with respect to the nature of the terminal load, this event indicates that the topological properties of the examined UN distribution BPL topology and the maximum CUD magnitude of measurement differences remain the most important factor concerning MLFLM performance. For that reason, the impact of the topological complexity of UN distribution BPL topologies on MLFLM performance is first examined in the following subsection. Also, since no significant MLFLM performance deviations are presented for different terminal loads, only one case (say, the case of short-circuit terminal load) is considered in the rest of this paper. Anyway, this is a typical procedure during the examination of MLFLM for the sake of the manuscript size reduction [33], [34], [38].

\subsection{The Impact of the Main Distribution Line Fault Location on MLFLM Performance}

Although each MDLFI presents strong dependence on the fault location [33], their combined operation under the aegis of MLFLM offers protection against the localization selectivity. Since each MDLFI offers safer results when the fault location lies near to its measurement site, the application of MDLFIs at the transmitting and receiving 
ends of the original UN distribution BPL topologies allows the cross check of the fault location as presented in Sec. 3.1 through the simultaneous minimization of MDLFIs.

Until now, only the fault case A has been examined where the main distribution line fault lies at $20 \mathrm{~m}$ from the transmitting end. In accordance with the previous MDLFI property description, it is expected that $\mathrm{MDLFI}_{1}$ gives a more accurate localization through its minimization in comparison with the respective one of $\mathrm{MDLFI}_{2}$ because the main distribution line fault lies near to $\mathrm{MDLFI}_{1}$ measurement point that is the transmitting end of the original UN distribution BPL topology. This event is valid either for the UN MV or for the UN LV BPL topologies.

In this subsection, the behavior of MDLFIs and consequently MLFLM is investigated for different location of main distribution line faults. In order to assess the performance of MDLFIs and MLFLM, Fault case B and C are applied where the fault location lies at $90 \mathrm{~m}$ and $190 \mathrm{~m}$ from the transmitting end, respectively. Indeed, in Fig. 5(a), MDLFIs are plotted versus the distance from the transmitting end when the terminal load is assumed to be short-circuit during the main distribution line fault for all the CUD cases examined so far (i.e., CUD case A, B and C). Note that the original urban MV BPL topology of Sec 2.2 and the Fault case B are assumed. In Fig. 5(b), same plots with Fig. 5(a) are drawn but for the case of the original UN LV BPL topology of Sec. 2.2. In Figs. 6(a) and 6(b), same curves with the respective Figs. 5(a) and 5(b) are given but for the Fault case C.

In all the cases, which have been examined in Figs. 3(a), 3(b), 5(a), 5(b), 6(a) and 6(b), MLFLM achieves to localize the main distribution line fault through the simultaneous minimization of MDLFIs regardless of the fault location. Actually, when main distribution line fault lies near to the transmitting end, $\mathrm{MDLFI}_{1}$ more easily identifies the fault location in comparison with $\mathrm{MDFLI}_{2}$-see Fault case A of Figs. 3(a) and 3(b)-. Conversely, when main distribution line fault lies near to the receiving end of the original UN distribution BPL topology $\mathrm{MDLFI}_{2}$ more easily copes with this case due to the aforementioned inherent MDLFI property of the fault distance selectivity -see Fault case $\mathrm{C}$ of Figs. 6(a) and 6(b)-. Finally, if main distribution line faults lie near to the middle of the original UN distribution BPL topology then the combined operation of MDLFIs is required -see Fault case B of Figs. 5(a) and 5(b)-. Also, MLFLM performance remains approximately the same either for UN MV BPL topologies or UN LV BPL ones.

During the localization of main distribution line faults, MDLFIs can be treated as filters of different types. When main distribution line faults lie near to the transmitting or receiving end, $\mathrm{MDLFI}_{1}$ resembles to a low pass or high pass filter, respectively. When main distribution line faults occur near to the middle of the examined UN distribution BPL topology, both MDLFIs can be considered as bandpass filters. This observation is very useful when intense measurement differences occur since then the localization of main distribution line faults comes from the matching of the pass regions of MDLFIs. In fact, this matching of the two MDLFI pass areas allows the determination of a region where the main distribution line faults lie and defines the general concept of the aforementioned MDLFI area method. Therefore, it is evident that the localization of main distribution line faults that lie near to the middle of UN distribution BPL networks remains the most difficult case of fault localization.

Apart from the fault location, MDLFI performance should be examined when different UN distribution BPL topologies are applied. Similarly to the OV MV BPL 


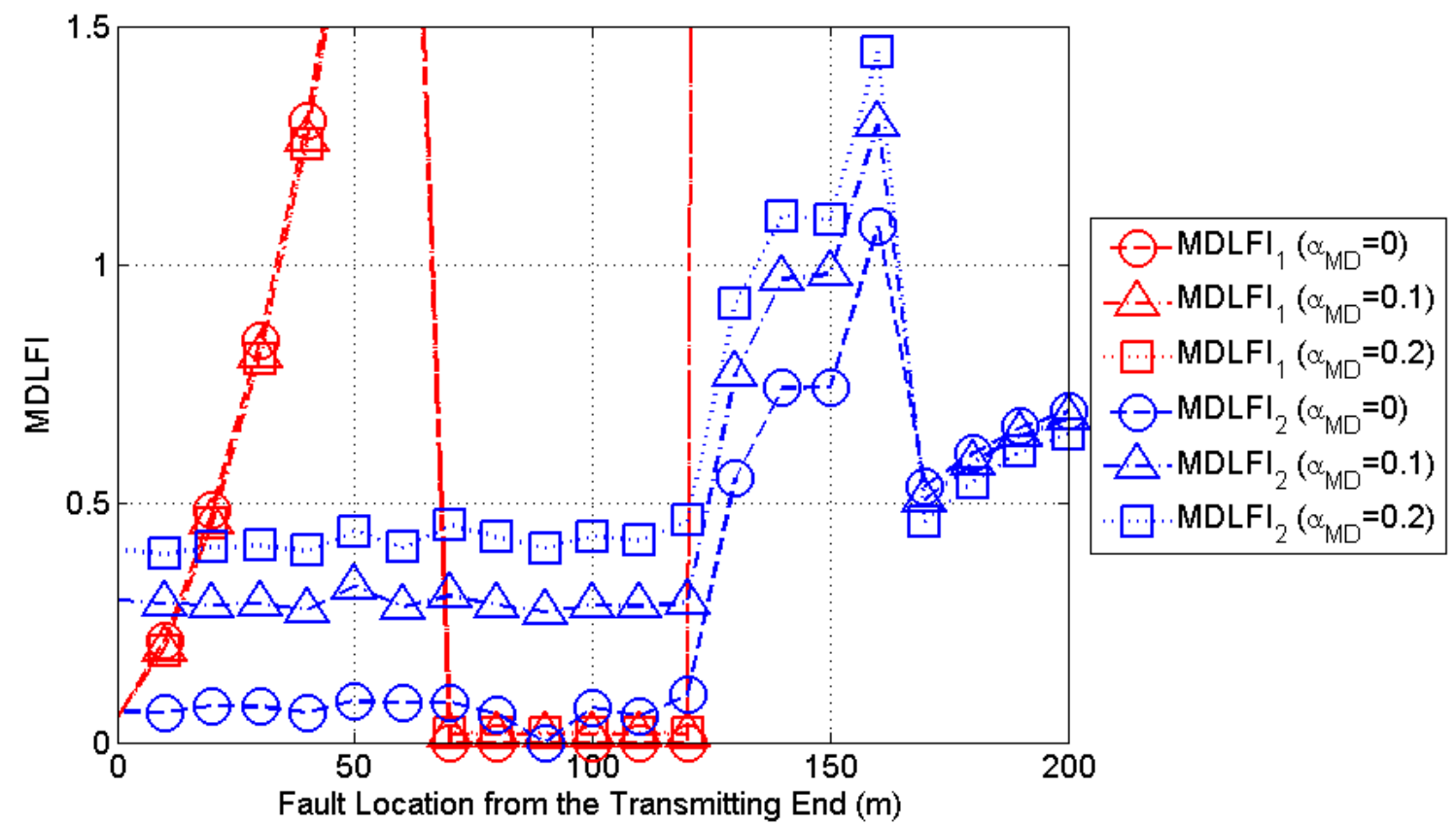

(a)

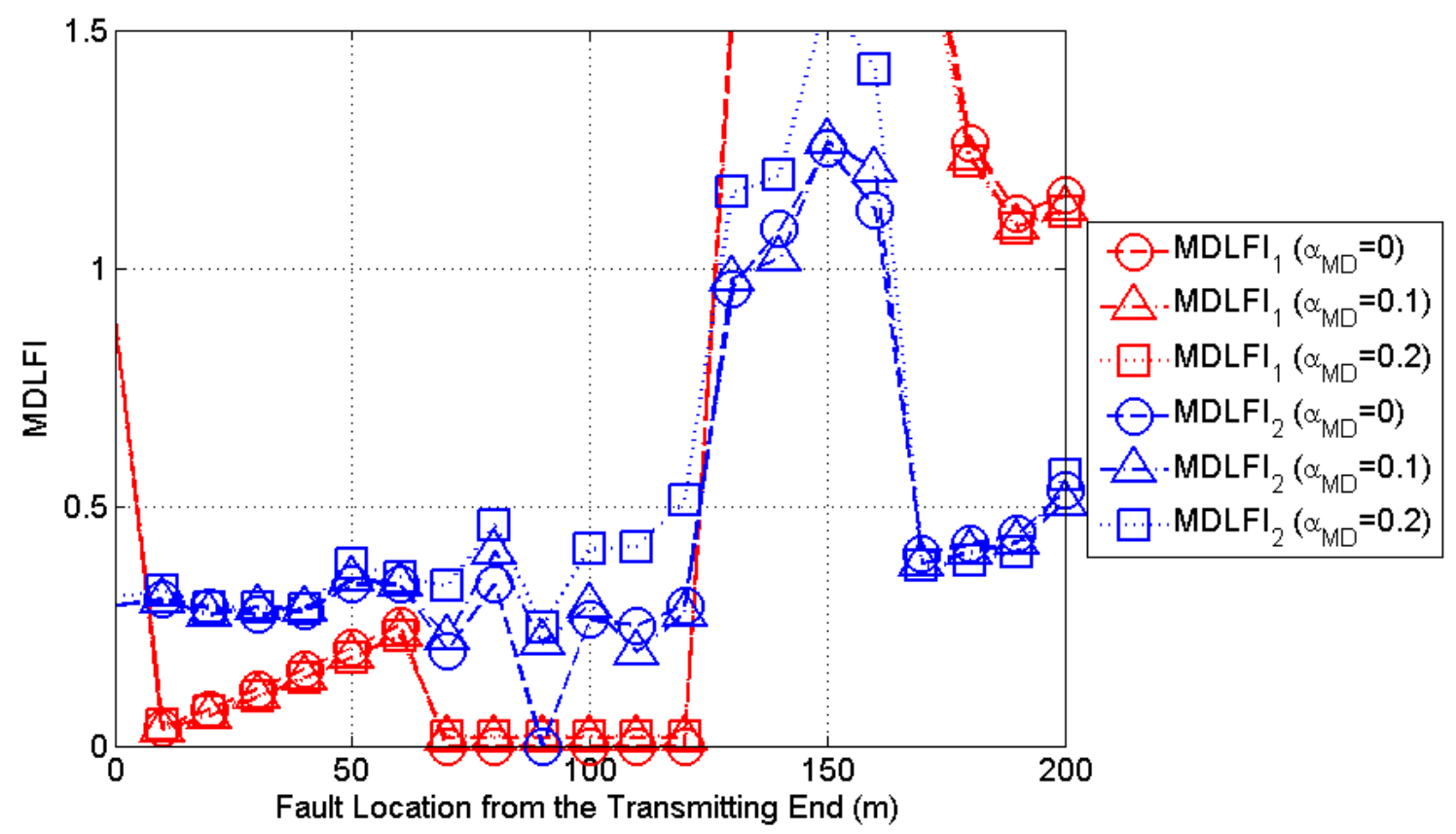

(b)

Figure 5. MDLFIs of the urban UN distribution BPL topologies versus the fault location from the transmitting end for various CUD cases when Fault case B occurs (the terminal load is assumed to be a short-circuit termination load and the fault location is at 90m). (a) MV. (b) LV. 


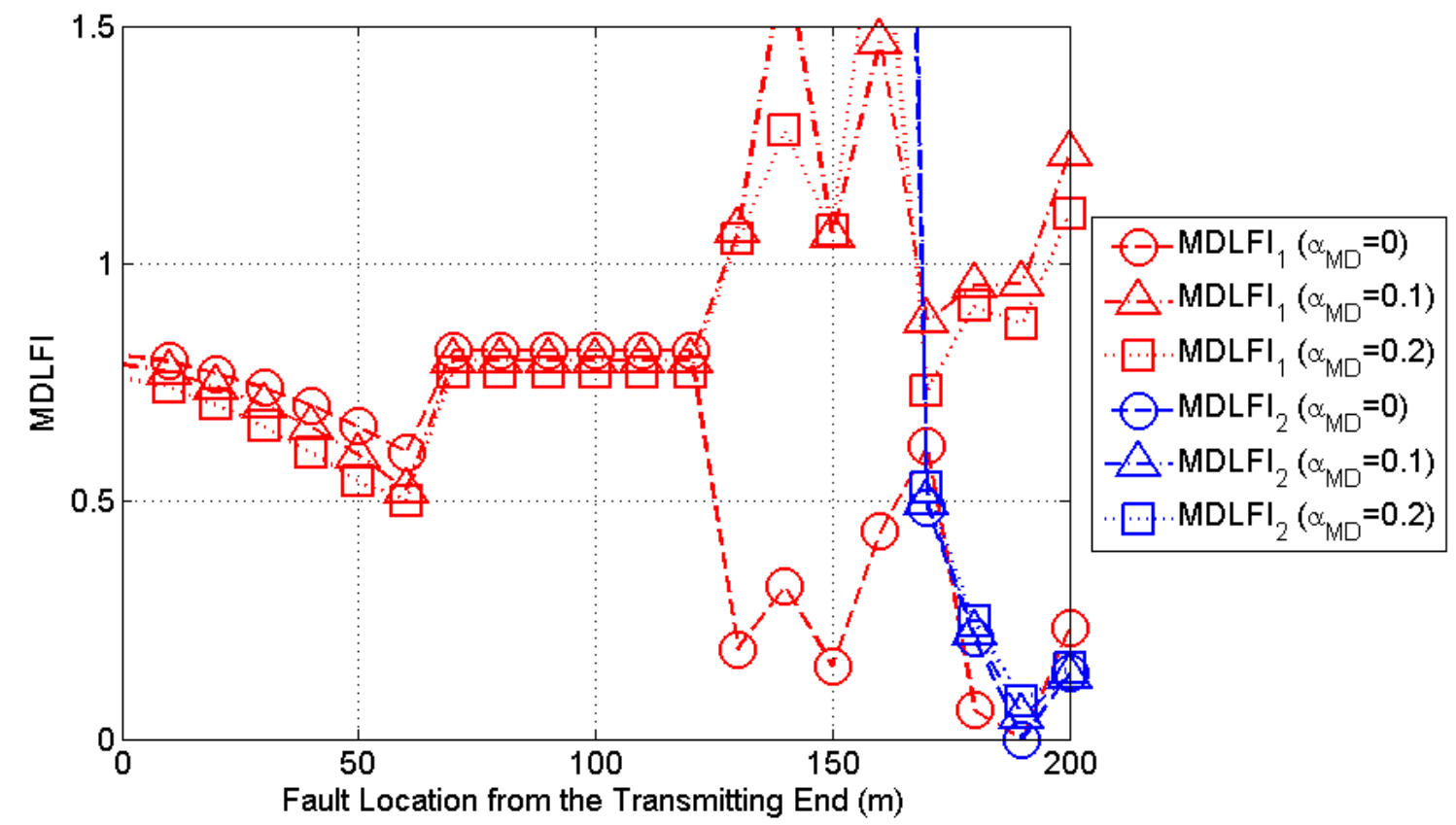

(a)

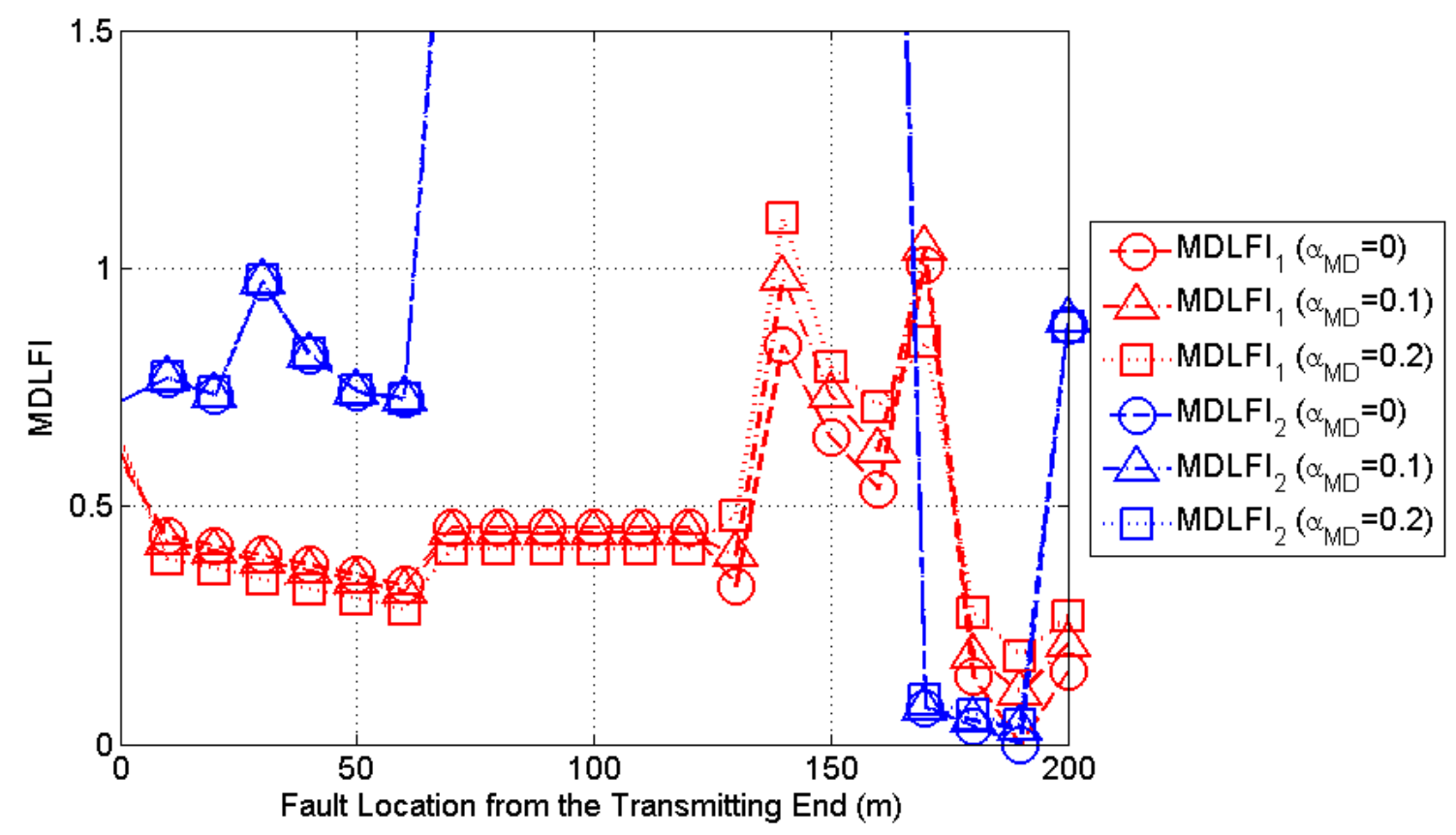

(b)

Figure 6. Same curves with Figure 5 but for the Fault case $C$ (the fault location is at 190m).

topologies [33], [34], [38], the topological complexity of UN distribution BPL topologies concerning their number and their length of branches affects either the measured coupling reflection coefficients or the form of MDLFIs or the minima of MDLFIs. 


\subsection{The Impact of the Original UN Distribution BPL Topologies on MLFLM Performance}

In this subsection, MLFLM performance is assessed for the other four indicative original UN distribution BPL topologies described in Sec. 2.2 -say, urban case B, suburban case, rural case and "LOS" case-

Indeed, in Fig. 7(a), MDLFIs are plotted versus the distance from the transmitting end of the original UN MV BPL topology of urban case B when the terminal load is assumed to be short-circuit. Note here that the Fault case A is assumed and all the available CUD cases are considered. In Fig. 7(b), same curves with Fig. 7(a) are given but for the case of the original UN LV BPL topology of urban case B. In Figs. 8, 9 and 10, same plots are drawn with Fig. 7 but for the suburban, rural and "LOS" cases, respectively.

From Figs. 3(a), 3(b), 7(a), 7(b), 8(a), 8(b), 9(a), 9(b), 10(a) and 10(b), the following conclusions regarding the MLFLM performance can be deduced:

- When CUD magnitude of measurement differences is equal to zero the exact localization of main distribution line faults occurs regardless of the type of UN distribution BPL network (i.e., MV or LV) and the examined BPL topology. In all the cases examined, there is a simultaneous minimization of MDFLIs at the fault position.

- When the CUD magnitude of measurement differences increases, MDLFIs start to take values greater than zero at the fault location. MDLFI ${ }_{1}$ acts as the primary MDLFI metric while $\mathrm{MDLFI}_{2}$ acts as the secondary one whether the examined main distribution line fault lies near to the transmitting end. It is clear from the previous figures that $\mathrm{MDFLI}_{1}$ minima always define the exact location of the main distribution line fault, which is located at $20 \mathrm{~m}$ from the transmitting end regardless of the examined UN distribution BPL topology. $\mathrm{MDLFI}_{2}$ presents its curve minima at $20 \mathrm{~m}$ in the majority of the cases examined.

- When measurement differences occur, MLFLM more easily localizes the occurred main distribution line faults in UN LV BPL networks than in UN MV BPL networks. As already been mentioned, measurement differences significantly affect coupling reflection coefficients of UN MV BPL topologies since their values have already been affected by the intense intrinsic characteristics of UN MV MTL configurations.

- When the examined BPL topologies are characterized by relative topological complexity (i.e., high number of branches of short branch lengths), the localization of the main distribution line faults more easily occurs. Since the terminations of the short branches critically influence the coupling reflection coefficients across the transmission path in accordance with the transmission theory [11], [16], the measurement differences can be easily detected due to their superimposition to an already existing coupling reflection coefficient pattern.

- Conversely, in BPL topologies that are characterized by low number of short branches, such as rural and "LOS" topologies of the UN distribution BPL topologies, the superimposed measurement differences drastically deteriorate the performance of MLFLM. In fact, when measurement differences start to present 


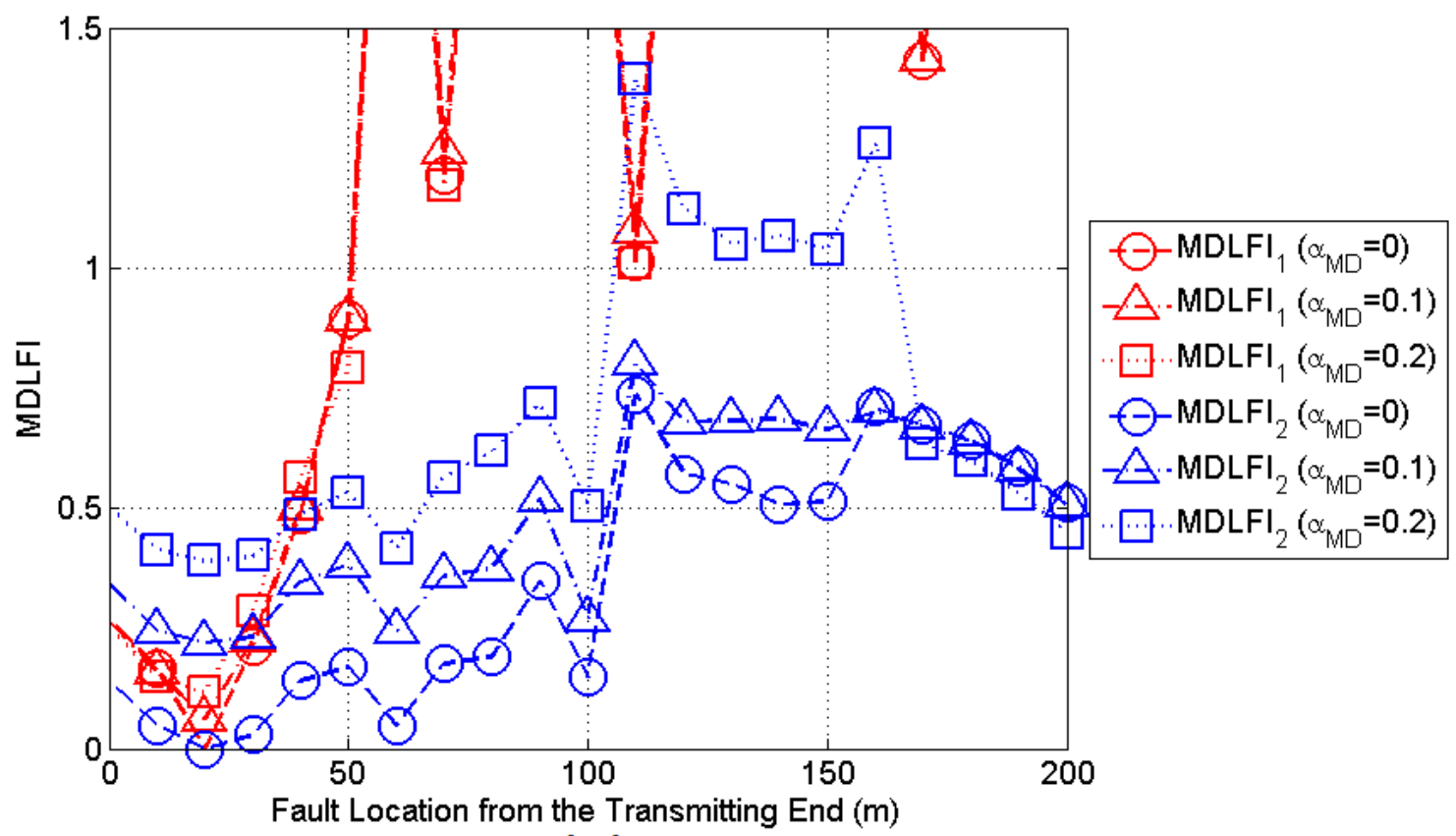

(a)

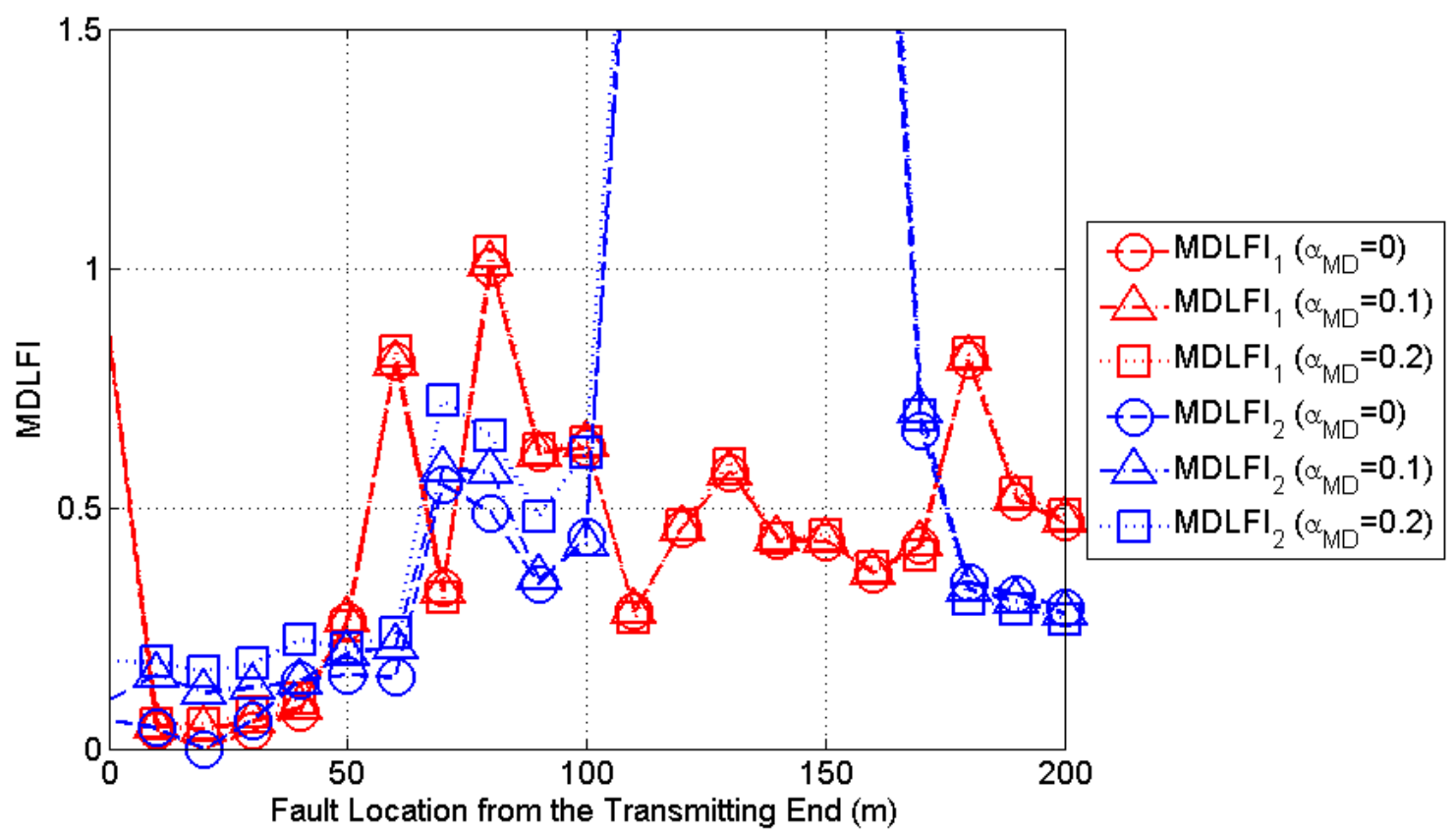

(b)

Figure 7. MDLFIs of the original UN BPL topology of urban case $B$ versus the fault location from the transmitting end for various CUD cases when Fault case A occurs (the terminal load is assumed to be a short-circuit termination load). (a) MV. (b) LV. 


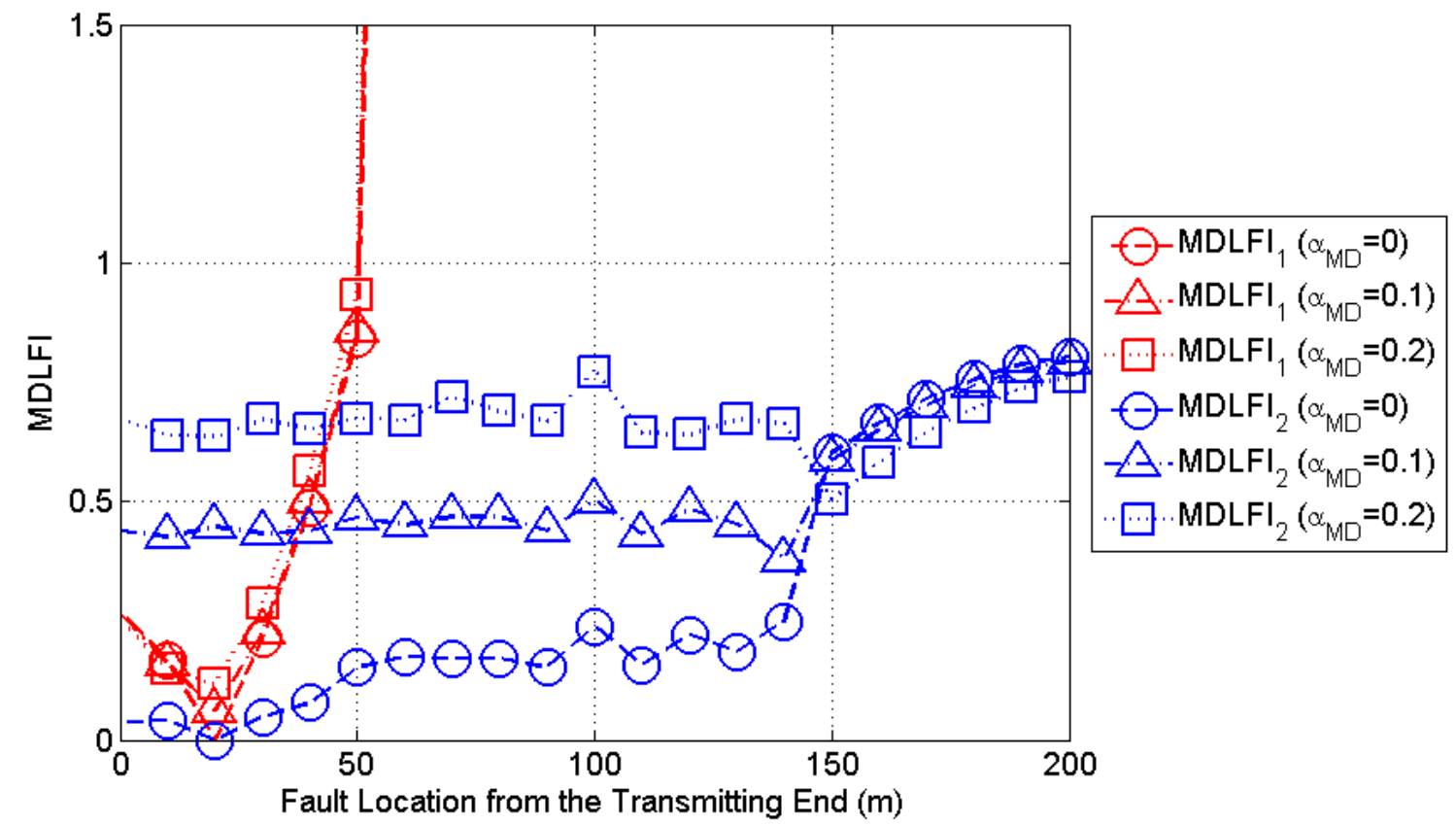

(a)

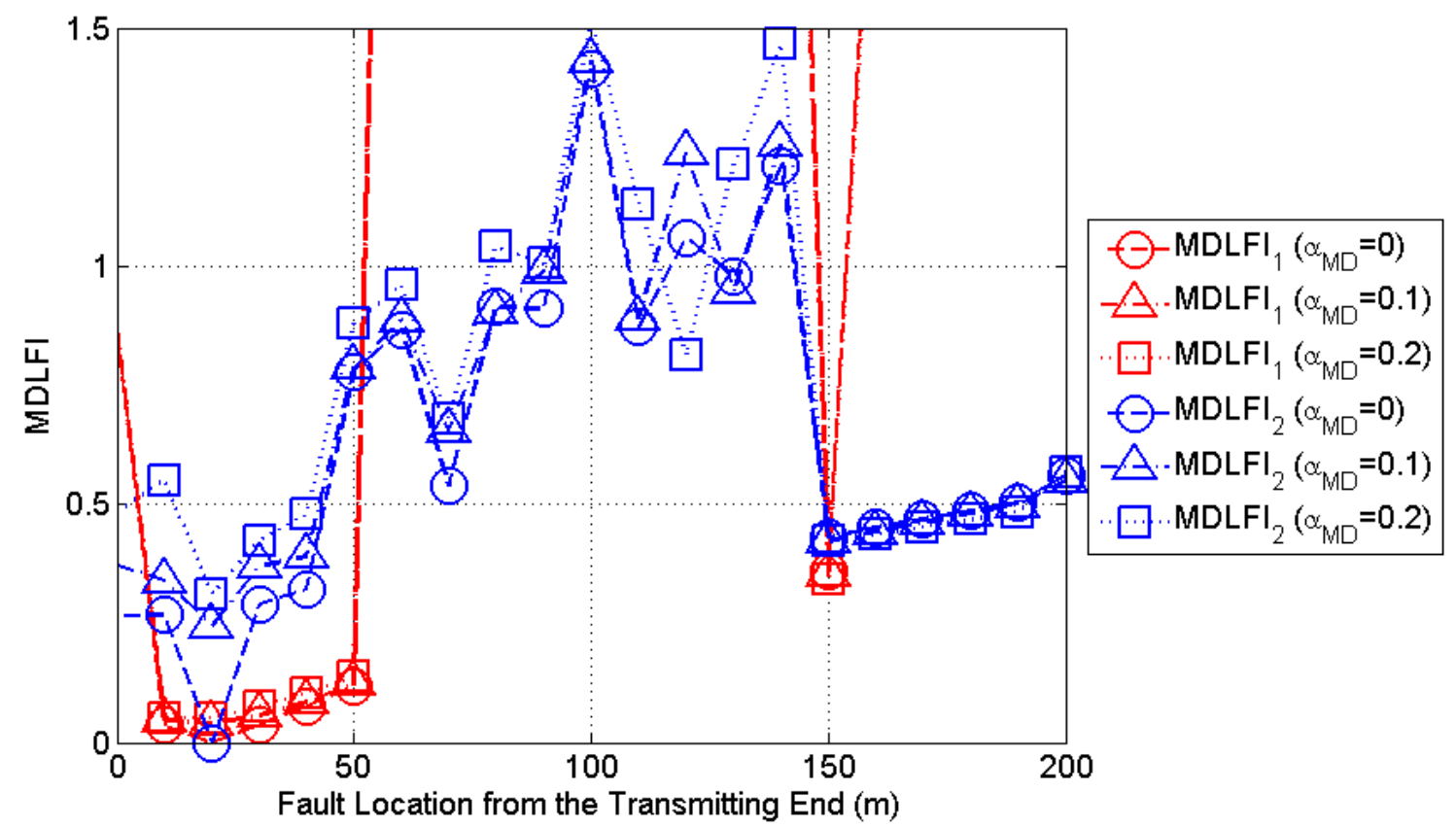

(b)

Figure 8. Same curves with Figure 7 but for the suburban case. 


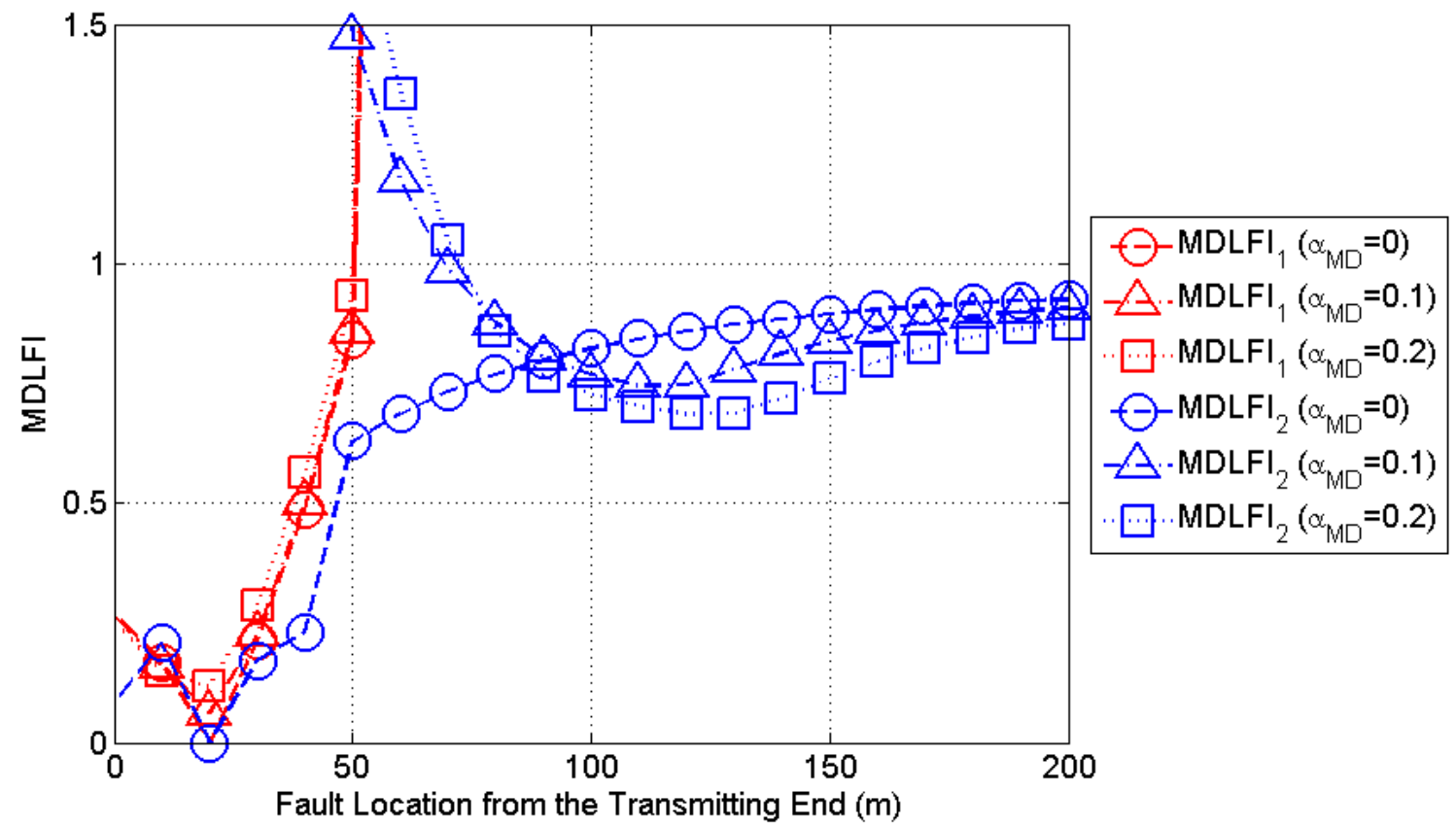

(a)

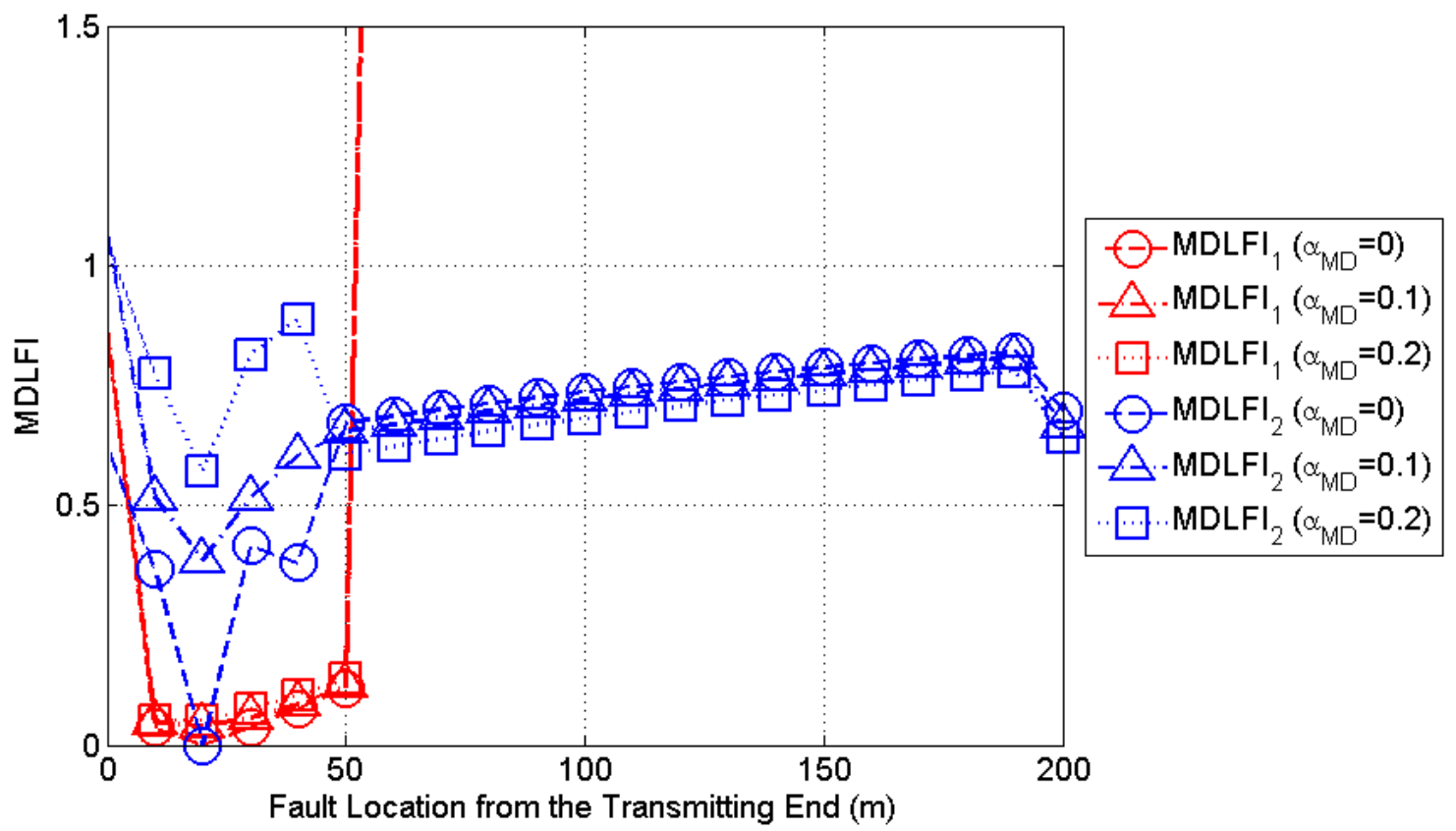

(b)

Figure 9. Same curves with Figure 7 but for the rural case. 


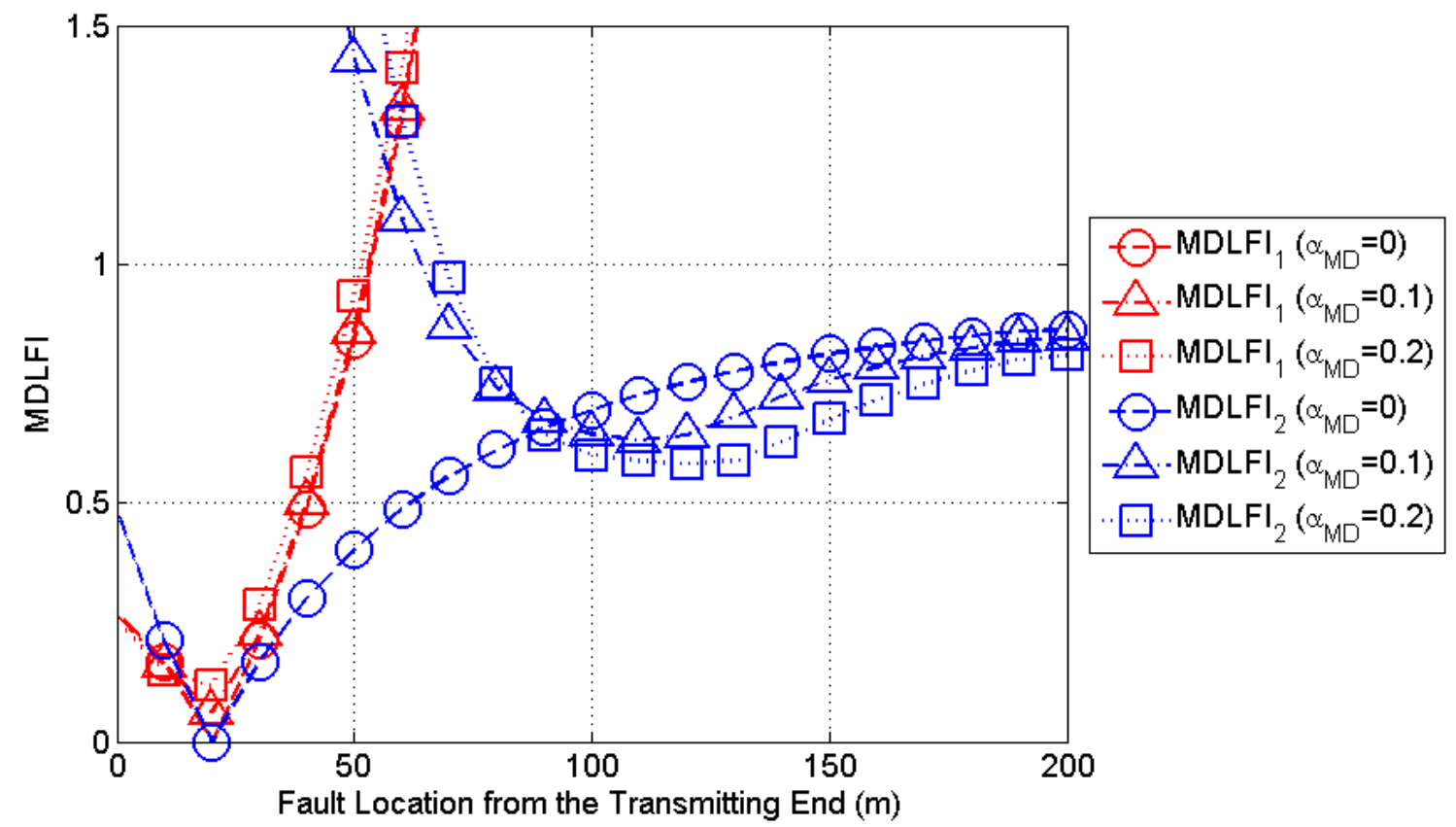

(a)

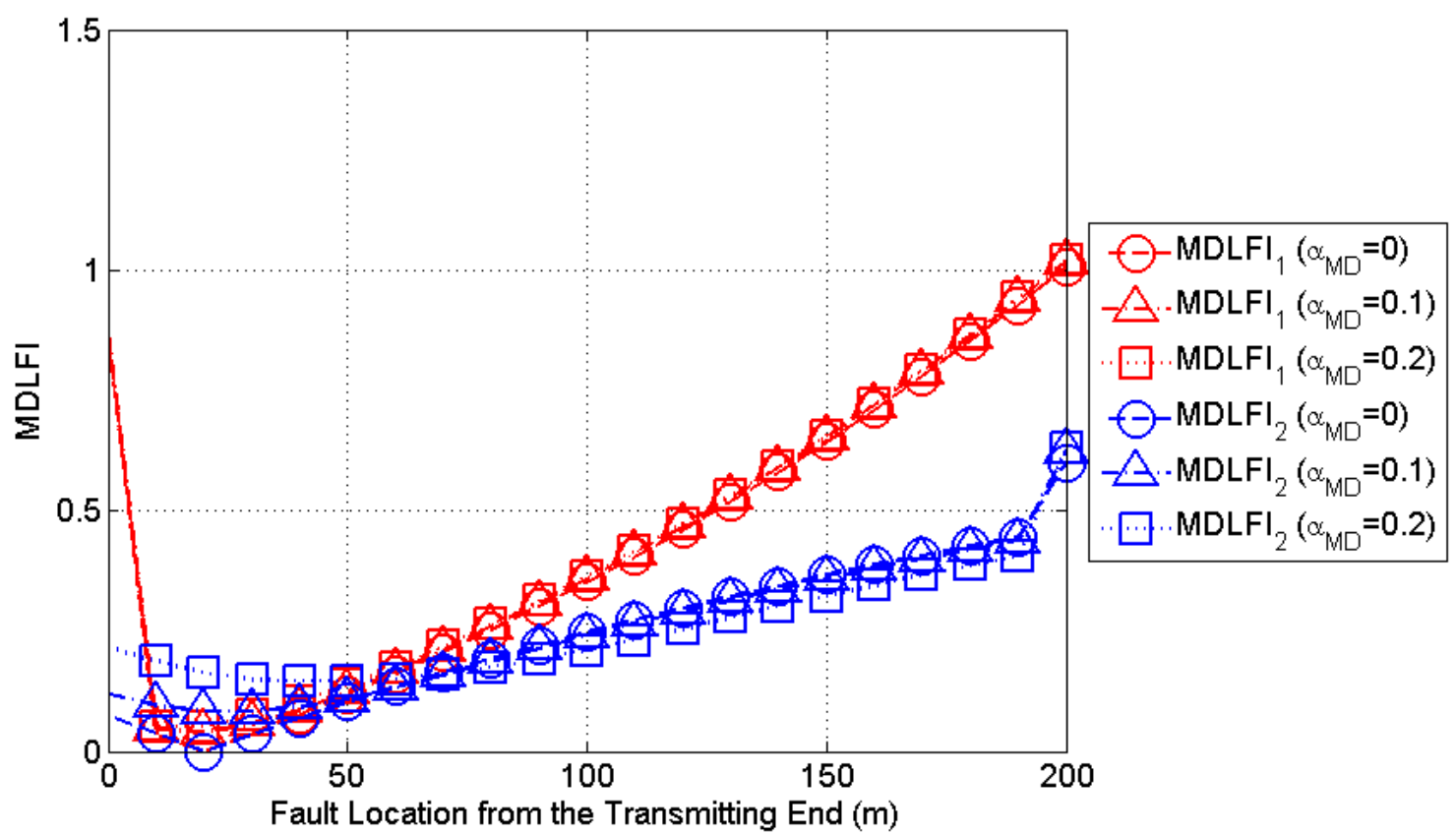

(b)

Figure 10. Same curves with Figure 7 but for the "LOS" case.

high CUD magnitudes, MDLFI of the measurement site that is the most distant to the main distribution line fault starts to present deviations. These deviations depend on the CUD magnitude and the type of distribution power grid. However, MDLFI that is the closest to the main distribution line fault steadily localizes the main distribution line fault through its minimization regardless of the maximum CUD value. Actually, the worst case scenario is given in Figs. 9(a) and 10(a) 
where it is clear that MDLFI 2 of the rural and "LOS" topologies of UN MV grid fails to localize the main distribution line fault when maximum CUD value exceeds 0.1 . The main distribution line fault can be localized by neither MDLFI area method nor MDLFI sum minimization. Therefore, in the cases of rural and "LOS" topologies of high channel attenuations, MLFLM is based on the MDLFI that presents a notch-type minimization (single MDLFI minimization case). Note here that the last proposed submethod includes only the case of UN MV grid when intense measurement differences occur. Synoptically, the localization of main distribution line faults through the simultaneous minimization of MDLFIs is safe in rural and "LOS" BPL topologies of UN distribution power grids when: (i) low maximum CUD values occur regardless of the UN distribution power grid type; and (ii) MLFLM is applied to UN LV grid.

\subsection{MLFLM Performance in OV and UN Distribution Power Grids}

Comparing findings of this paper that concern the MLFLM performance in UN distribution power grids with the respective ones of [38] that concern the MLFLM performance in OV distribution power grids, several similarities but also differences can be outlined during the application of MLFLM, namely:

- In all the cases examined where the measurement differences have been neglected, MLFLM have successfully localized main distribution line faults by the simultaneous minimization of $\mathrm{MDLFI}_{1}$ and $\mathrm{MDLFI}_{2}$ regardless of the distribution power grid. In fact, both MDLFIs receive zero value at the location of the main distribution line fault.

- Regardless of the location of a main distribution line fault, MLFLM can localize the faults through the simultaneous minimization of MDLFIs. Even if the main distribution line fault is located at the middle of the original BPL topology and measurement differences are considered, the minimization of MDFLIs occurs at this position in a band pass filter way. The simultaneous minimization of MDLFIs defines the normal operation of MLFLM that deals with the main distribution line faults in the majority of the BPL topologies in OV and UN distribution power grids.

- As measurement differences increase so do the minima of MDLFIs at the location of the main distribution line fault. The values of minima differ from zero.

- In the cases of intense measurement differences, MDLFIs may not present simultaneous minimization at the location of the main distribution line fault. In these cases, the general form of MDLFIs entails the location of the main distribution line fault. Anyway, the MDLFI that is closer to the main distribution line fault present a notch type minimization and MLFLM decision is based on this regardless of the intensity of the occurred measurement differences (single MDLFI minimization case). Note that both MDLFIs present notch type minimization regardless of the intensity of the occurred measurement differences when the main distribution line fault is located near to the middle of the transmission path of the examined BPL topology.

- Even if measurement differences occur, the localization of the main distribution line faults remains safer in the cases of aggravated BPL topologies, such as urban and suburban topologies, due to the inherent intense changes of coupling 
reflection coefficients. Actually, MDLFIs of these cases present notch type minimization at the location of the main distribution line faults and this is explained by the operation of PMAs.

- The localization of main distribution line faults in rural and "LOS" cases becomes a challenging issue for MLFLM especially when significant measurement differences occur and the channel attenuation of the examined BPL topologies is high.

- OV MV and UN LV BPL topologies are treated by MLFLM in the same way since their channel attenuation remains low. If measurement differences are low, the localization of the main distribution line faults comes from the simultaneous minimization of MDLFIs. If measurement differences become high, the localization of the main distribution line fault is based on either the MDLFI area method or the MDFLI sum minimization.

- Due to the UN MV MTL configuration considered in this paper, UN MV BPL topologies present significant higher channel attenuations in comparison with the respective ones of OV MV and UN LV BPL topologies. The absence of a rich multipath environment has as a result the performance deterioration of MLFLM when a main distribution line fault needs to be localized. Therefore, in rural and "LOS" topologies, when measurement differences remain low, the localization of the main distribution line faults comes from the simultaneous minimization of MDLFIs. If measurement differences are intense and the main distribution line fault lies near to either the transmitting end or the receiving end, the single MDLFI minimization is adopted. If measurement differences are intense but the main distribution line fault lies near to the middle of the examined topology, either the MDLFI area method or the MDFLI sum minimization can be adopted.

In accordance with [33], [34], [38], these three papers have achieved to cover the identification and localization methodology of main distribution line faults through the proposal and application of MLFLM methodology in OV distribution BPL networks. In this paper, MLFLM methodology has been extended by incorporating three submethods in order to cope with the localization problem of main distribution line faults in UN distribution BPL networks. A complete methodology of identifying and localizing possible faults and instabilities across distribution power grids is now available.

\section{Conclusions}

In this paper, which extends the application of MLFLM from OV MV BPL networks to UN distribution BPL networks, the detailed presentation and the performance assessment of MLFLM have been demonstrated. Given the existence of a random main distribution line fault, MLFLM has successfully localized its location across the transmission path of various UN MV and UN LV BPL topologies despite the imposed performance deterioration that is added by the measurement differences.

In accordance with [38], this paper has briefly outlined the required steps to create MLFLM database, define MDLFIs and apply MDLFIs to MLFLM database in order to localize the main distribution line faults. After the theoretical presentation of MFLFM, a number of case scenarios has been reported so that MLFLM performance is 
evaluated. During these case scenarios, the impact of some critical parameters, such as the type of UN distribution power grid (i.e., UN MV and UN LV power grid), the intensity of measurement differences, the location of the main distribution line fault and the nature of the main distribution line fault (i.e., short- or open- circuit terminal load), on the MLFLM performance has been assessed indicating the localization accuracy of MLFLM in the vast majority of the cases examined.

Synopsizing the results, MLFLM can very accurately localize main distribution line faults regardless of their location across the transmission path of UN distribution BPL topologies due to the combined used of MDLFIs. In addition, as it is obvious, MLFLM performance mainly depends on the intensity of the occurred measurement differences allowing the accurate localization of measurement differences even if maximum CUD magnitudes reach up to 0.2. Also, MLFLM can more easily localize main distribution line faults in more complex UN distribution BPL topologies (i.e., urban, aggravated urban and suburban BPL topologies) rather in less complex ones (i.e., rural and "LOS" BPL topologies). This is due to the fact that MLFLM accuracy is based on the pattern recognition of coupling reflection coefficients since MDLFIs are related with PMAs. Furthermore, MLFLM performance depends on the type of the UN distribution power grid since it remains higher in the cases of low overall channel attenuation (such as UN LV BPL topologies and the majority of UN MV BPL topologies).

Although MLFLM can very accurately localize main distribution line faults in the vast majority of the cases examined during its normal operation (i.e., simultaneous minimization of MDLFIs), three new submethods, which accompanies MLFLM, have been proposed in order to cope with some special cases where MLFLM presents deviations. More specifically, the first two submethods, which are the MDLFI area method and the MDLFI sum minimization, have been proposed in order to localize main distribution line faults when measurement differences are equal or greater than 0.2. The third submethod, that is the single MDLFI minimization and is treated as the lastresort method, has been proposed in order to localize main distribution line faults when the following extreme conditions coexist: (i) UN distribution BPL topologies of high channel attenuation and low topological complexity (e.g., rural and "LOS" UN MV BPL topologies); (ii) measurement differences with maximum CUD magnitudes that are equal or greater than 0.1 ; and (iii) main distribution line faults that lie near to the transmitting or receiving end of the original BPL topology.

A complete methodology of localizing main distribution line faults in $\mathrm{OV}$ and UN distribution BPL networks has been proposed. The already accurate MLFLM has been enriched with three additional submethods in order to localize main distribution line faults in the most challenging cases of distribution power grids.

\section{CONFLICTS OF INTEREST}

The author declares that there is no conflict of interests regarding the publication of this paper. 


\section{References}

[1] S. Ezzine, F. Abdelkefi, J. P. Cances, V. Meghdadi, and A. Bouallégue, "Evaluation of PLC Channel Capacity and ABER Performances for OFDM-Based Two-Hop Relaying Transmission," Hindawi Wireless Communications and Mobile Computing, vol. 2017, ArticleID 4827274, pp. 1-12, 2017.

[2] F. A. Pinto-Benel, M. Blanco-Velasco, and F. Cruz-Roldán, "Throughput Analysis for Wavelet OFDM in Broadband Power Line Communications,” 2017. [Online]. Available: https://pdfs.semanticscholar.org/55ee/c64f1b4533f1be2d21db993b48eda3d96f38. pdf (accessed on 12/28/2017).

[3] IEEE P1901, "Draft Standard for Broadband over Power Line Networks: Medium Access Control and Physical Layer Specifications", 2010. [Online]. Available: http://grouper.ieee.org/groups/1901/index.html (accessed on 12/28/2017).

[4] A. G. Lazaropoulos and P. G. Cottis, "Transmission characteristics of overhead medium voltage power line communication channels," IEEE Trans. Power Del., vol. 24, no. 3, pp. 1164-1173, Jul. 2009.

[5] A. G. Lazaropoulos and P. G. Cottis, "Capacity of overhead medium voltage power line communication channels," IEEE Trans. Power Del., vol. 25, no. 2, pp. 723-733, Apr. 2010.

[6] A. G. Lazaropoulos and P. G. Cottis, "Broadband transmission via underground medium-voltage power lines-Part I: transmission characteristics," IEEE Trans. Power Del., vol. 25, no. 4, pp. 2414-2424, Oct. 2010.

[7] A. G. Lazaropoulos and P. G. Cottis, "Broadband transmission via underground medium-voltage power lines-Part II: capacity," IEEE Trans. Power Del., vol. 25, no. 4, pp. 2425-2434, Oct. 2010.

[8] A. G. Lazaropoulos, "Broadband transmission characteristics of overhead highvoltage power line communication channels," Progress in Electromagnetics Research B, vol. 36, pp. 373-398, 2012. [Online]. Available: http://www.jpier.org/PIERB/pierb36/19.11091408.pdf

[9] A. G. Lazaropoulos, "Capacity Performance of Overhead Transmission MultipleInput Multiple-Output Broadband over Power Lines Networks: The Insidious Effect of Noise and the Role of Noise Models," Trends in Renewable Energy, vol. 2, no. 2, pp. 61-82, Jan. $2016 . \quad$ [Online]. Available:

http://futureenergysp.com/index.php/tre/article/view/23

[10] Homeplug, AV2Whitepaper, 2011, [Online]. Available: http://www.homeplug.org/techresources/resources/

[11] A. G. Lazaropoulos, "Factors Influencing Broadband Transmission Characteristics of Underground Low-Voltage Distribution Networks," IET Commun., vol. 6, no. 17, pp. 2886-2893, Nov. 2012.

[12] A. G. Lazaropoulos, "Towards broadband over power lines systems integration: Transmission characteristics of underground low-voltage distribution power lines," Progress in Electromagnetics Research B, 39, pp. 89-114, 2012. [Online]. Available: http://www.jpier.org/PIERB/pierb39/05.12012409.pdf

[13] A. G. Lazaropoulos, "Broadband transmission and statistical performance properties of overhead high-voltage transmission networks,"Hindawi Journal of Computer Networks and Commun., 2012, article ID 875632, 2012. [Online]. Available: http://www.hindawi.com/journals/jcnc/aip/875632/ 
[14] A. G. Lazaropoulos, "Towards modal integration of overhead and underground low-voltage and medium-voltage power line communication channels in the smart grid landscape: model expansion, broadband signal transmission characteristics, and statistical performance metrics (Invited Paper)," ISRN Signal Processing, vol. 2012, Article ID 121628, 17 pages, 2012. [Online]. Available: https://www.hindawi.com/journals/isrn/2012/121628/

[15] A. G. Lazaropoulos, "Review and Progress towards the Common Broadband Management of High-Voltage Transmission Grids: Model Expansion and Comparative Modal Analysis," ISRN Electronics, vol. 2012, Article ID 935286, pp. $1-18,2012 . \quad$ [Online]. Available: http://www.hindawi.com/isrn/electronics/2012/935286/

[16] A. G. Lazaropoulos, "Review and Progress towards the Capacity Boost of Overhead and Underground Medium-Voltage and Low-Voltage Broadband over Power Lines Networks: Cooperative Communications through Two- and ThreeHop Repeater Systems," ISRN Electronics, vol. 2013, Article ID 472190, pp. 1-19, 2013. [Online]. Available: http://www.hindawi.com/isrn/electronics/aip/472190/

[17] A. G. Lazaropoulos, "Green Overhead and Underground Multiple-Input MultipleOutput Medium Voltage Broadband over Power Lines Networks: EnergyEfficient Power Control," Springer Journal of Global Optimization, vol. 2012 / Print ISSN 0925-5001, pp. 1-28, Oct. 2012.

[18] P. Amirshahi and M. Kavehrad, "High-frequency characteristics of overhead multiconductor power lines for broadband communications," IEEE J. Sel. Areas Commun., vol. 24, no. 7, pp. 1292-1303, Jul. 2006.

[19] T. Sartenaer, "Multiuser communications over frequency selective wired channels and applications to the powerline access network" Ph.D. dissertation, Univ. Catholique Louvain, Louvain-la-Neuve, Belgium, Sep. 2004. [Online\} Available: https://dial.uclouvain.be/pr/boreal/en/object/boreal\%3A5010/datastream/PDF 12/ view (accessed on 12/28/2017).

[20] T. Calliacoudas and F. Issa, "'Multiconductor transmission lines and cables solver," An efficient simulation tool for plc channel networks development," presented at the IEEE Int. Conf. Power Line Communications and Its Applications, Athens, Greece, Mar. 2002.

[21] A. G. Lazaropoulos, "Best L1 Piecewise Monotonic Data Approximation in Overhead and Underground Medium-Voltage and Low-Voltage Broadband over Power Lines Networks: Theoretical and Practical Transfer Function Determination," Hindawi Journal of Computational Engineering, vol. 2016, Article ID 6762390, 24 pages, 2016. doi:10.1155/2016/6762390. [Online]. Available: https://www.hindawi.com/journals/jcengi/2016/6762390/cta/

[22] A. G. Lazaropoulos, "Measurement Differences, Faults and Instabilities in Intelligent Energy Systems - Part 1: Identification of Overhead High-Voltage Broadband over Power Lines Network Topologies by Applying Topology Identification Methodology (TIM)," Trends in Renewable Energy, vol. 2, no. 3, pp. 85 - 112, Oct. 2016.

[23] A. G. Lazaropoulos, "Measurement Differences, Faults and Instabilities in Intelligent Energy Systems - Part 2: Fault and Instability Prediction in Overhead High-Voltage Broadband over Power Lines Networks by Applying Fault and Instability Identification Methodology (FIIM)," Trends in Renewable Energy, vol. 
2, no. 3, pp. 113 - 142, Oct. 2016. [Online]. Available: http://futureenergysp.com/index.php/tre/article/view/27/33

[24] I. C. Demetriou and M. J. D. Powell, "Least squares smoothing of univariate data to achieve piecewise monotonicity,"IMA J. of Numerical Analysis, vol. 11, pp. 411-432, 1991.

[25] I. C. Demetriou and V. Koutoulidis, "On Signal Restoration by Piecewise Monotonic Approximation", in Lecture Notes in Engineering and Computer Science: Proceedings of The World Congress on Engineering 2013, London, U.K., Jul. 2013, pp. 268-273.

[26] I. C. Demetriou, "An application of best $L 1$ piecewise monotonic data approximation to signal restoration," IAENG International Journal of Applied Mathematics, vol. 53, no. 4, pp. 226-232, 2013.

[27] I. C. Demetriou, "L1PMA: A Fortran 77 Package for Best L1 Piecewise Monotonic Data Smoothing," Computer Physics Communications, vol. 151, no. 1, pp. 315-338, 2003.

[28] I. C. Demetriou, "Data Smoothing by Piecewise Monotonic Divided Differences," Ph.D. Dissertation, Department of Applied Mathematics and Theoretical Physics, University of Cambridge, Cambridge, 1985.

[29] I. C. Demetriou, "Best L1 Piecewise Monotonic Data Modelling," Int. Trans. Opl Res., vol. 1, no. 1, pp. 85-94, 1994.

[30] http://cpc.cs.qub.ac.uk/summaries/ADRF

[31] I. C. Demetriou, "Algorithm 863: L2WPMA, a Fortran 77 package for weighted least-squares piecewise monotonic data approximation," ACM Transactions on Mathematical Software (TOMS), vol. 33, no.1, pp. 6, 2007.

[32] I. C. Demetriou, "L2CXCV: A Fortran 77 package for least squares convex/concave data smoothing," Computer physics communications, vol. 174, no.8,pp. 643-668, 2006.

[33] A. G. Lazaropoulos, "Main Line Fault Localization Methodology in Smart Grid Part 1: Extended TM2 Method for the Overhead Medium-Voltage Broadband over Power Lines Networks Case," Trends in Renewable Energy, vol. 3, no. 3, pp. $2 \quad-\quad 25, \quad 2017 . \quad$ [Online]. Available: http://futureenergysp.com/index.php/tre/article/view/36/pdf

[34] A. G. Lazaropoulos, "Main Line Fault Localization Methodology in Smart Grid Part 2: Extended TM2 Method, Measurement Differences and L1 Piecewise Monotonic Data Approximation for the Overhead Medium-Voltage Broadband over Power Lines Networks Case," Trends in Renewable Energy, vol. 3, no. 3, pp. $26 \quad-\quad 61, \quad 2017 . \quad$ [Online]. Available: http://futureenergysp.com/index.php/tre/article/view/37/pdf

[35] A. G. Lazaropoulos, "Power Systems Stability through Piecewise Monotonic Data Approximations - Part 1: Comparative Benchmarking of L1PMA, L2WPMA and L2CXCV in Overhead Medium-Voltage Broadband over Power Lines Networks," Trends in Renewable Energy, vol. 3, no. 1, pp. 2 - 32, Jan. 2017. [Online]. Available: http://futureenergysp.com/index.php/tre/article/view/29/34

[36] A. G. Lazaropoulos, "Power Systems Stability through Piecewise Monotonic Data Approximations - Part 2: Adaptive Number of Monotonic Sections and Performance of L1PMA, L2WPMA and L2CXCV in Overhead Medium-Voltage Broadband over Power Lines Networks," Trends in Renewable Energy, vol. 3, no. 
1, pp. $33-60, \quad$ Jan. 2017. [Online]. Available: http://futureenergysp.com/index.php/tre/article/view/30/35

[37] A. G. Lazaropoulos, "Improvement of Power Systems Stability by Applying Topology Identification Methodology (TIM) and Fault and Instability Identification Methodology (FIIM) - Study of the Overhead Medium-Voltage Broadband over Power Lines (OV MV BPL) Networks Case," Trends in Renewable Energy, vol. 3, no. 2, pp. 102 - 128, Apr. 2017. [Online]. Available: http://futureenergysp.com/index.php/tre/article/view/34/pdf

[38] A. G. Lazaropoulos, "Main Line Fault Localization Methodology in Smart Grid Part 3: Main Line Fault Localization Methodology (MLFLM)," Trends in Renewable Energy, vol. 3, no. 3, pp. 62 - 81, 2017. [Online]. Available: http://futureenergysp.com/index.php/tre/article/view/38/pdf

[39] OPERA1, D5: Pathloss as a function of frequency, distance and network topology for various LV and MV European powerline networks. IST Integrated Project No 507667, Apr. 2005.

[40] P. C. J. M. van der Wielen, "On-line detection and location of partial discharges in medium-voltage power cables" Ph.D. dissertation, Tech. Univ. Eindhoven, Eindhoven, the Netherlands, Apr. 2005.

[41] P. C. J. M. van der Wielen, E. F. Steennis, and P. A. A. F. Wouters, "Fundamental aspects of excitation and propagation of on-line partial discharge signals in threephase medium voltage cable systems," IEEE Trans. Dielectr. Electr. Insul., vol. 10, no. 4, pp. 678-688, Aug. 2003.

[42] M. Tang, and M. Zhai, "Research of transmission parameters of four-conductor cables for power line communication," in Proc. Int. Conf. on Computer Science and Software Engineering, Wuhan, China, Dec. 2008, vol. 5, pp. 1306-1309.

[43] A. G. Lazaropoulos, "A Panacea to Inherent BPL Technology Deficiencies by Deploying Broadband over Power Lines (BPL) Connections with Multi-Hop Repeater Systems," Bentham Recent Advances in Electrical \& Electronic Engineering, vol. 10, no. 1, pp. 30-46, 2017.

[44] A. G. Lazaropoulos, "Underground Distribution BPL Connections with $(\mathrm{N}+1)$ hop Repeater Systems: A Novel Capacity Mitigation Technique," Elsevier Computers and Electrical Engineering, vol. 40, pp. 1813-1826, 2014.

[45] A. G. Lazaropoulos, "Broadband over Power Lines (BPL) Systems Convergence: Multiple-Input Multiple-Output (MIMO) Communications Analysis of Overhead and Underground Low-Voltage and Medium-Voltage BPL Networks (Invited Paper)," ISRN Power Engineering, vol. 2013, Article ID 517940, pp. 1-30, 2013. [Online].

Available: http://www.hindawi.com/isrn/power.engineering/2013/517940/

[46] DLC+VIT4IP, D1.2: Overall system architecture design DLC system architecture. FP7 Integrated Project No 247750, Jun. 2010.

[47] T. Sartenaer and P. Delogne, "Deterministic modelling of the (Shielded) outdoor powerline channel based on the multiconductor transmission line equations," IEEE J. Sel. Areas Commun., vol. 24, no. 7, pp. 1277-1291, Jul. 2006.

[48] OPERA1, D44: Report presenting the architecture of plc system, the electricity network topologies, the operating modes and the equipment over which PLC access system will be installed, IST Integr. Project No 507667, Dec. 2005.

[49] N. Theethayi, "Electromagnetic interference in distributed outdoor electrical systems, with an emphasis on lightning interaction with electrified railway 
network," Ph.D. dissertation, Uppsala Univ., Uppsala, Sweden, Sep. 2005, [Online]. Available: http://uu.divaportal.org/smash/get/diva2:166746/FULLTEXT01

[50] J. Anatory, N. Theethayi, R. Thottappillil, M. M. Kissaka, and N. H. Mvungi, "The influence of load impedance, line length, and branches on underground cable Power-Line Communications (PLC) systems," IEEE Trans. Power Del., vol. 23, no. 1, pp. 180-187, Jan. 2008.

[51] J. Anatory, N. Theethayi, and R. Thottappillil, "Power-line communication channel model for interconnected networks-Part II: Multiconductor system," IEEE Trans. Power Del., vol. 24, no. 1, pp. 124-128, Jan. 2009.

[52] J. Anatory, N. Theethayi, R. Thottappillil, M. M. Kissaka, and N. H. Mvungi, "The effects of load impedance, line length, and branches in typical low-voltage channels of the BPLC systems of developing countries: transmission-line analyses," IEEE Trans. Power Del., vol. 24, no. 2, pp. 621-629, Apr. 2009.

[53] A. G. Lazaropoulos, "Designing Broadband over Power Lines Networks Using the Techno-Economic Pedagogical (TEP) Method - Part II: Overhead LowVoltage and Medium-Voltage Channels and Their Modal Transmission Characteristics," Trends in Renewable Energy, vol. 1, no. 2, pp. 59-86, Jun. 2015. [Online]. Available: http://futureenergysp.com/index.php/tre/article/view/6/16

[54] A. G. Lazaropoulos, "Designing Broadband over Power Lines Networks Using the Techno-Economic Pedagogical (TEP) Method - Part I: Overhead High Voltage Networks and Their Capacity Characteristics (Invited Review Article)," Trends in Renewable Energy, vol. 1, no. 1, pp. 16-42, Mar. 2015. [Online]. Available: http://futureenergysp.com/index.php/tre/article/view/2

[55] A. Canova, N. Benvenuto, and P. Bisaglia, "Receivers for MIMO-PLC channels: Throughput comparison," in Proc. IEEE Int. Symp. Power Line Communications and Its Applications, Rio de Janeiro, Brazil, Mar. 2010, pp. 114-119.

[56] D. Schneider, J. Speidel, L. Stadelmeier, and D. Schill, "Precoded spatial multiplexing MIMO for inhome power line communications," in Proc. IEEE Global Telecommunications Conference, New Orleans, LA, USA, Nov./Dec. 2008, pp. 1-5.

[57] M. Zimmermann and K. Dostert, "Analysis and modeling of impulsive noise in broad-band powerline communications," IEEE Trans. Electromagn. Compat., vol. 44, no. 1, pp. 249-258, Feb. 2002.

[58] T. Esmailian, F. R. Kschischang, and P. G. Gulak, "In-building power lines as high-speed communication channels: Channel characterization and a test channel ensemble," Int. J. Commun. Syst., vol. 16, pp. 381-400, May 2003.

Article copyright: (C) 2018 Athanasios G. Lazaropoulos. This is an open access article distributed under the terms of the Creative Commons Attribution 4.0 International License, which permits unrestricted use and distribution provided the original author and source are credited. 